\title{
cons-9410216--3
}

SAND94-2170C

\section{Risk Contribution from Low Power, Shutdown, and Other Operational Modes Beyond Full Power*}

\author{
D. W. Whitehead \\ T. D. Brown ${ }^{2}$ \\ T-L $\mathrm{Chu}^{3}$ \\ W. T. Pratt ${ }^{3}$
}

'Risk Assessment and Systems Modeling Department 6412

Sandia National Laboratories

Albuquerque, New Mexico 87185-0747

${ }^{2}$ Accident Analysis and Consequence Assessment Department 6413

Sandia National Laboratories

Albuquerque, New Mexico 87185-0748

${ }^{3}$ Department of Advanced Technology

Brookhaven National Laboratory

Upton, New York 11973

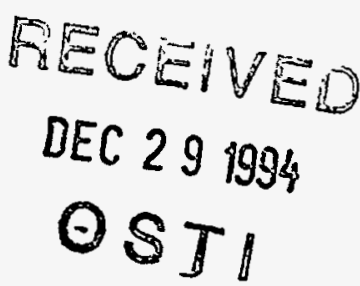

During 1989 the Nuclear Regulatory Commission (NRC) initiated an extensive program to carefully examine the potential risks during low power and shutdown operations. Two plants, Surry (a pressurized water reactor) and Grand Gulf (a boiling water reactor), were selected for study by Brookhaven National Laboratory and Sandia National Laboratories, respectively.

The program objectives included assessing the risks of severe accidents initiated during plant operational states other than full power and comparing estimated core damage frequencies, important accident sequences, and other qualitative and quantitative results with full power accidents as assessed in NUREG-1150. The scope included a Level 3 probabilistic risk assessment (PRA) for traditional internal events and a Level 1 PRA on fire, flooding, and seismically induced core damage sequences.

A phased approach was used in Level 1. In Phase 1 the concept of plant operational states (POSs) was developed to provide a better representation of the plant as it transitions from power to nonpower operation. This included a coarse screening analysis of all POSs to identify vulnerable plant configurations, to characterize (on a high, medium, or low basis) potential frequencies of core damage accidents, and to provide a foundation for a detailed Phase 2 analysis.

In Phase 2, selected POSs from both Grand Gulf and Surry were chosen for detailed analysis. For Grand Gulf, POS 5 (approximately cold shutdown as defined by Grand Gulf Technical Specifications) during a refueling outage was selected. For Surry, three POSs representing the time the plant spends in midloop operation were chosen for analysis. These included POS 6 and POS 10 of a refueling outage and POS 6 of a drained maintenance outage.

Level 1 and Level 2/3 results from both the Surry and Grand Gulf analyses are presented.

\footnotetext{
This work was supported by the United States Nuclear Regulatory Commission and was performed at Brookhaven National Laboratory and Sandia National Laboratories, which are operated for the U.S. Department of Energy under Contract Numbers DE-AC02-76CH00016 and DE-AC04-94AL85000, respectively.
} 


\section{DISCLAIMER}

Portions of this document may be illegible in electronic image products. Images are produced from the best available original document. 


\section{Introduction}

During 1989 the Nuclear Regulatory Commission (NRC) initiated an extensive program to carefully examine the potential risks during low power and shutdown operations. Two plants, Surry (a pressurized water reactor) and Grand Gulf ( $a$ boiling water reactor), were selected as the plants to be studied by Brookhaven National Laboratory and Sandia National Laboratories, respectively.

The program objectives included assessing the risks of severe accidents initiated during plant operational states other than full power operation and comparing the estimated core damage frequencies, risks, important accident sequences, and other qualitative and quantitative results with those accidents initiated during full power operation as assessed in NUREG-1150.

A phased approach was used in the Level 1 program. In Phase 1 the concept of plant operational states (POSs) was developed to allow the analysts to obtain a better representation of the plant as it transitions from power to nonpower operation. This phase consisted of a coarse screening analysis for all POSs to identify potential vulnerable plant configurations, to characterize (on a high, medium, or low basis) the potential frequencies of core damage accidents, and to provide a foundation for a detailed Phase 2 analysis.

In Phase 2, selected POSs from both Grand Gulf and Surry were chosen for detailed analysis. For Grand Gulf, POS 5 (approximately cold shutdown as defined by Grand Gulf Technical Specifications) during a refueling outage was selected. For Surry, three POSs representing the time the plant spends in midloop operation were chosen for analysis. These included POS 6 and POS 10 of a refueling outage and POS 6 of a drained maintenance outage.

During the preliminary quantification of the accident sequences in Phase 2, it was found that the decay heat at which the accident-initiating event occurs is an important parameter that determines both the success criteria for the mitigating functions and the time available for operator actions. In order to better account for the decay heat, a "time windown approach was developed. In this approach, time windows after shutdown were defined based on the success criteria established for the methods used to mitigate the accident. Section 2 documents the results from the work performed during the Phase 2 analysis of the Grand Gulf plant, and Section 3 documents the results from the Surry Phase 2 analysis.

\section{Grand Gulf Results and Conclusions}

The results and conclusions presented below come directly from NUREG/CR-6143, Vols. $2-6{ }^{[1-6]}$

\subsection{Level 1 Results}

\subsubsection{Quantitative Results for Traditional Internal Events}

\section{Individual Sequences}

The total core damage frequency (CDF) presented here results from combining the mean CDFs from all 38 sequence cut sets for the 28 sequences that survived through the time window analysis. For POS 5 during a refueling outage at Grand Gulf, the sum of the mean $\mathrm{CDF}$ from the surviving sequences is $2.1 \mathrm{E}-6$ per calendar year for intemally initiated events (excluding internal fires and floods).

\begin{tabular}{|c|c|r|}
\hline \hline IE Class & $\begin{array}{c}\text { Mean } \\
\text { CDF }\end{array}$ & $\begin{array}{c}\text { \% Contribution } \\
\text { To CDF }\end{array}$ \\
\hline LOCA diversion & $1.3 \mathrm{E}-06$ & 62 \\
\hline LOSP/blackout & $7.0 \mathrm{E}-07$ & 33 \\
\hline Other & $9.9 \mathrm{E}-08$ & 5 \\
\hline Total & $2.1 \mathrm{E}-06$ & 100 \\
\hline
\end{tabular}

Figure 1 shows the contributions of the various initiating events to core damage frequency. Two classes of initiating events dominate the results from this study. As can be seen above, loss-of-coolant accident (LOCA)/diversion and loss of offsite power (LOSP)/blackout constitute approximately $95 \%$ of the total core damage frequency.

Within these two classes of sequences, two types of accidents are dominant. They are:

- Blackout - Initiated by a loss of offsite power, a subsequent loss of all onsite ac power either by loss of the diesel 
generators (DGs) directly or indirectly--by the loss of some DG support system, and the failure to restore either offsite or onsite ac power before core damage occurs; and

- Flooding Containment - Initiated by an event requiring the injection of water into the vessel, out the SRVs to the suppression pool, and finally out the open lower containment personnel lock. owing to the failure of the operators to either close the lower personnel lock or to control the injection of the water into the vessel. The resulting flood is assumed to cause failure of the equipment necessary to prevent core damage.

From a CDF vs. time window aspect, time window 2 is the most important; Figure 2 indicates that it contributes 58 percent of the total core damage frequency. Another way to present the core damage frequency information is to plot the fractional contribution of each initiator group by time window. This results in Figure 3 . From this figure it can be seen that for:

\section{Time Window 1}

The core damage frequency is split between the LOCA/diversion and the LOSP/blackout groups (42 and 58 percent respectively).

\section{Time Window 2}

The core damage frequency is split among the three groups (41 percent - LOCA/diversion, 50 precent LOCA/blackout, and 9 percent - Other)

\section{Time Window 3}

All core damage frequency results from the LOCA/diversion group.

One final way to present the core damage frequency information is to plot the percent contribution to the total core damage frequency and the percent of time spent in each time window vs. the three time windows on the same graph. From Figure 4 it can be seen that even though the plant spends only 21 percent of the time in time window 2, this window contributes 58 percent to the total core damage frequency. Figure 4 also indicates that time window 3 contributes 35 percent of the total core damage frequency, yet 76 percent of the time is spent in this window. Thus, from Figures 3 and 4 we see that time window 2 is the most important time regime for POS 5 during a refueling outage.

\section{Total Plant Model}

The CDF results from the uncertainty analysis of the total plant model for traditional internal events (i.e., an uncertainty analysis of all of the sequence cut sets at the same time) using 1000 samples are as follows:

$\begin{array}{ll}\text { Mean Value } & 2.0 \mathrm{E}-006 \\ \text { 5th Percentile Value } & 4.1 \mathrm{E}-007 \\ \text { Median Value } & 1.3 \mathrm{E}-006 \\ \text { 95th Percentile Value } & 5.4 \mathrm{E}-006\end{array}$

Comparing the results of this study with those obtained in the NUREG/CR-4550 study of Grand Gulf and the Grand Gulf individual plant examination (IPE), we find that the mean CDF from the total plant model obtained in this study (2.0E-6) is 50 percent of the NUREG/CR-4550 value of $4.0 \mathrm{E}-6$ and almost an order of magnitude less than IPE results of 1.7E-5. In addition, the results from this study indicate that, unlike the NUREG/CR-4550 results, sequences other than those initiated by LOSP (e.g., LOCAs) contribute significantly to the core damage frequency.

\subsubsection{Quantitative Results from Internal Fire Events}

A detailed screening analysis was performed which showed that most plant areas had a negligible contribution to the frequency of fire-induced core damage. A detailed fire propagation analysis was performed for four fire zones. There were no plant areas which were found to have a contribution to core damage frequency greater than the truncation limit of $1 E-8$; thus, no fire sequences survived. 


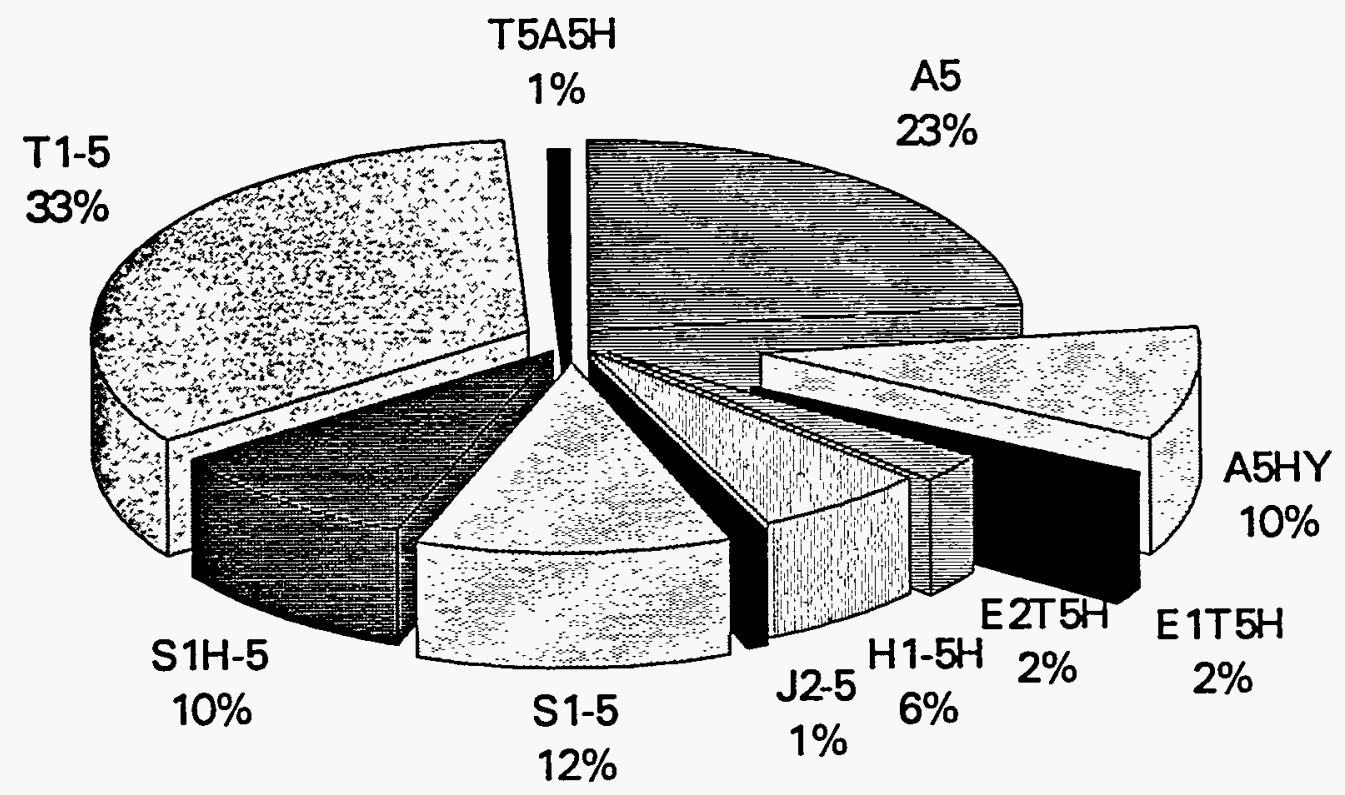

Figure 1 Contribution to CDF by Initiating Event

A5 - Large LOCA during nonhydro conditions

A5HY - Large LOCA during hydro conditions

E1T5H - Isolation of shutdown cooling common suction line

E2T5H - Loss of shutdown cooling common suction line

$\mathrm{Hl}-5 \mathrm{H}$ - Diversion to the suppression pool via the residual heat removal system

J2-5 - LOCA in the residual heat removal system

S1-5 - Intermediate LOCA during nonhydro conditions

S1H-5 - Intermediate LOCA during hydro conditions

T1-5 - Loss of offsite power

T5A5H - Loss of standby service water system

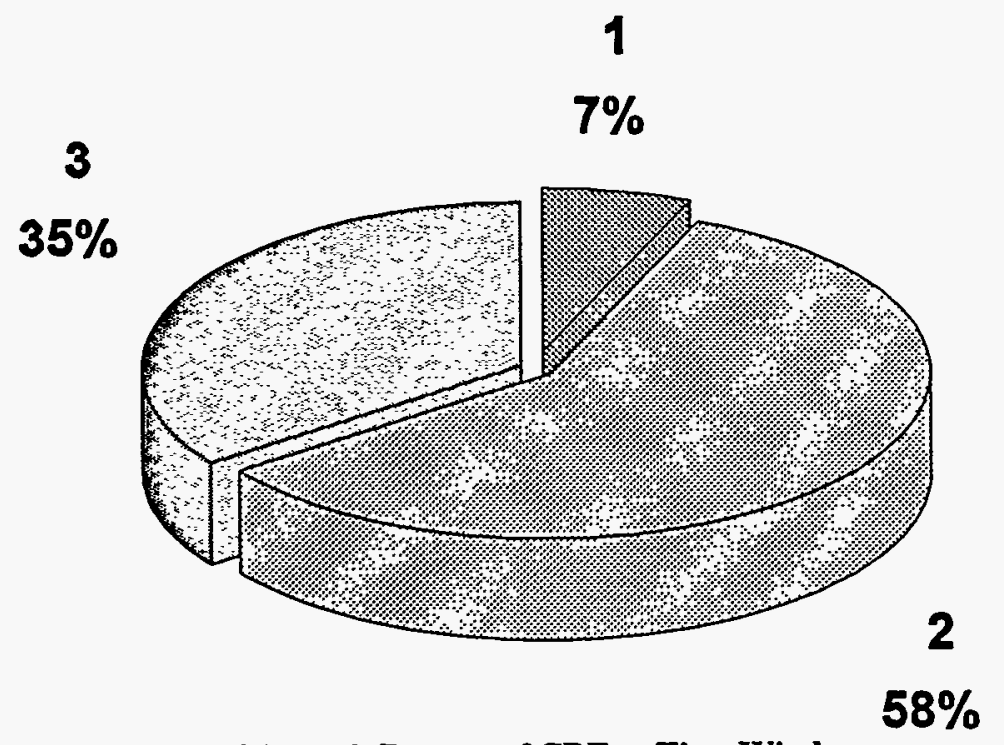

Figure 2 Percent of CDF vs Time Window 


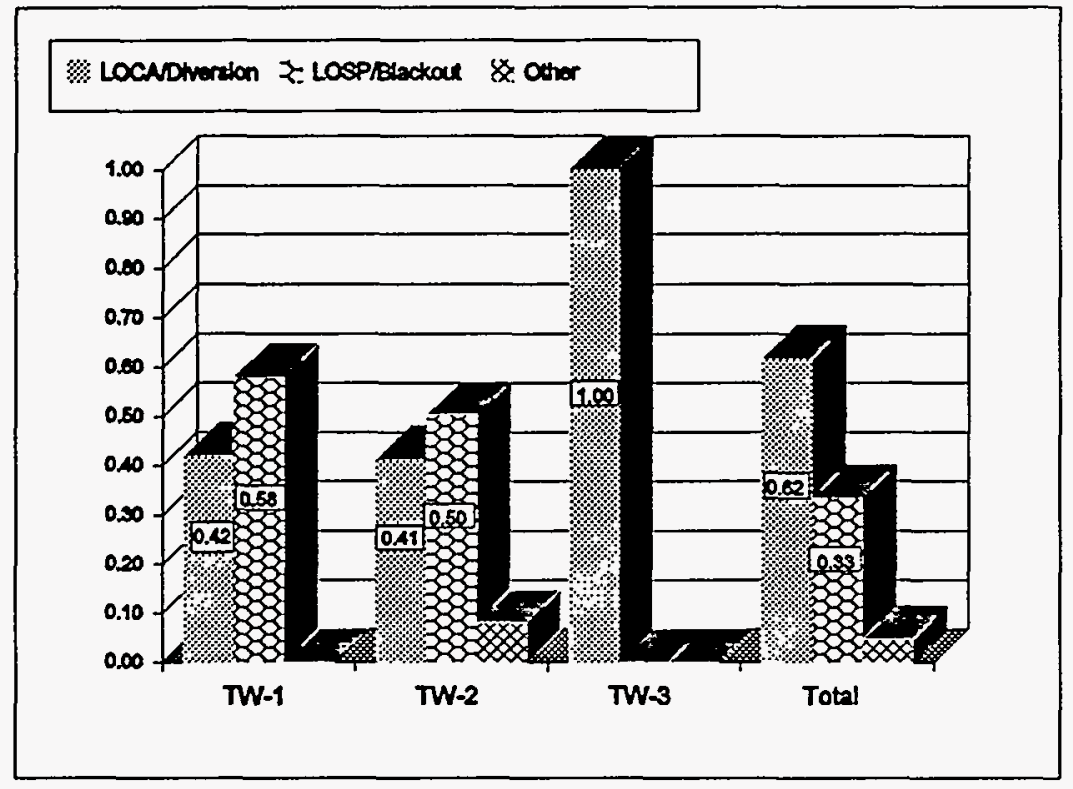

Figure 3 Fractional Contribution to CDF by IE Group vs Time Window

\section{$\mathbb{N}$ Percent of CDF Percent of time in TW}

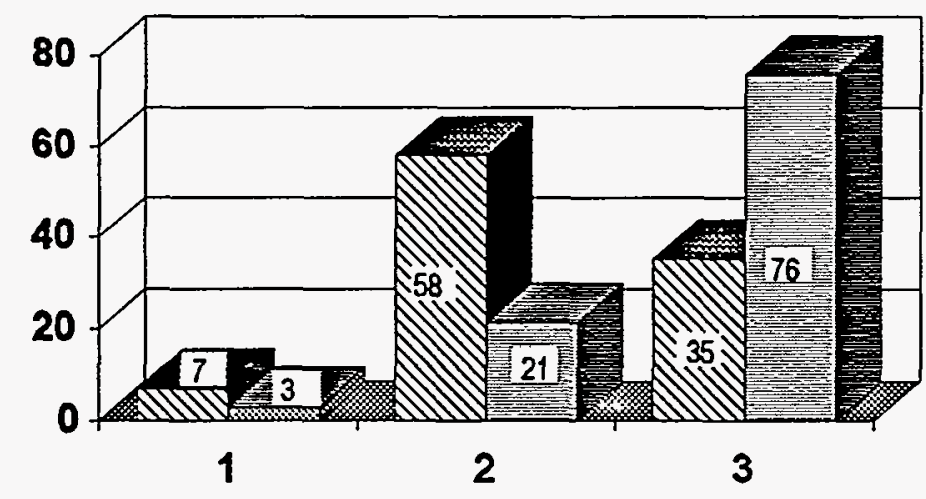

Figure 4 Percent of CDF and Percent of Time in Time Window vs. Time Window 


\subsubsection{Quantitative Results for Internal Flooding Events}

A single sequence survived through the time window analysis. This sequence is initiated by a break in a fire water system pipe. The resulting flood from this initiator disables Divisions 1,2 , and 3 Class $1 \mathrm{E}$ ac and dc power. Given the severity of this postulated accident sequence, no operator recovery was postulated. The mean core damage frequency for this sequence is $2.3 \mathrm{E}-8$ per year. The 5 th and 95 th percentiles are $8.2 \mathrm{E}-11$ and $8.6 \mathrm{E}-6$ per year, respectively.

\subsubsection{Quantitative Results from Seismic Events}

The CDF results of the seismic analyses for earthquake-initiated accidents during POS 5 for a refueling outage are as follows:

\section{For the LLNL (1993) Hazard Curves}

$\begin{array}{ll}\text { 5th percentile } & 2.1 \mathrm{E}-11 \\ \text { Median } & 2.4 \mathrm{E}-9 \\ \text { Mean } & 7.1 \mathrm{E}-8 \\ \text { 95th percentile } & 2.2 \mathrm{E}-7\end{array}$

\section{For the EPRI Hazard Curves}

$\begin{array}{ll}\text { 5th percentile } & 2.5 \mathrm{E}-12 \\ \text { Median } & 2.0 \mathrm{E}-10 \\ \text { Mean } & 2.5 \mathrm{E}-9 \\ \text { 95th percentile } & 1.1 \mathrm{E}-8\end{array}$

\subsubsection{Qualitative Results}

Insights from Traditional Internal Events

Systems Insights

Characteristics of the plant design are a major factor affecting the likelihood of core damage while in cold shutdown. For Grand Gulf, the following plant characteristics are most important:

1. Shutdown cooling system components are not rated for full pressure, but automatic isolation occurs on either high pressure or on low level;

2. Use of the residual heat removal system for shutdown cooling requires recirculation, either forced or natural, to prevent pressurization transients;

3. Owing to density and pump head effects, recirculation is sensitive to actual level in the core region. The water level in the core region is related to but not equal to measured level in the downcomer;

4. At decay heat levels of concern, flooding-induced dryout of the core at atmospheric pressure will not occur, and the core can be cooled by steaming with a maximum of 250 gpm makeup;

5. To steam at low pressure, opening one safety relief valve in relief mode is sufficient to maintain pressure low enough that the low head pumps in the emergency cooling system can provide sufficient makeup;

6. Opening one safety relief valve in relief requires operator action, dc power, and air,

7. In using the emergency core cooling system in a water solid mode, opening of two safety relief valves in the relief mode prevents overpressurizing the shutdown cooling system components, both in the residual heat removal system and in the alternate decay heat removal system (ADHRS), regardless of the pump(s) used;

8. In using the emergency core cooling system in a water solid mode, opening one safety relief valve in the relief mode prevents overpressurizing the components in the residual heat removal system used in shutdown cooling, but components in the auxiliary decay heat removal system may be overpressurized;

9. Isolation of the shutdown cooling system allows the core to be cooled at full pressure by steaming on one safety relief valve at its safety setpoint, and no operator action or support systems are required to operate the valve in the safety mode;

10. Use of emergency core cooling systems in a water solid mode does not require suppression pool makeup, in the short term, to compensate for vessel fill; 
11. Water can be injected into the vessel at low pressure from both service water and diesel-driven firewater pumps.

\section{Operations Insights}

In POS 5 (i.e., cold shutdown), the requirements of the technical specifications for the operability of systems and components are much less stringent than for power operation. The actual availability of systems depends on plantspecific practices, and on the reason for transitioning the plant to cold shutdown -- in this case, a refueling outage.

For Grand Gulf, the following practices have an important impact on the ability to cool the core in POS 5:

1. At least two safety relief valves are maintained operable for both relief and safety operation;

2. Automatic isolation of the low-pressure shutdown cooling system is not bypassed, but is maintained on both high pressure and low level;

3. Some subsystems of the emergency core cooling system are available most of the time.

\section{Insights from Internal Fire Events}

The fire-induced core damage frequency is lower than other fire risk assessments at power owing to a number of factors. First, this plant operational state represents only 3 percent of the time at shutdown, and shutdown fire frequencies are similar to those at power. This immediately reduces core damage frequency. Second, even if active electromechanical safety-related equipment is damaged by fire, an initiating event may not necessarily occur. For instance, for the loss of the turbine building cooling water (TBCW) initiator to result from fire-related damage, multiple operational pumps must fail. These pumps and their associated cabling have sufficient separation to make it highly unlikely that a single fire could lead to failure of all pumps. Many initiating events at shutdown were screened because of physical separation criteria. Even for the unscreened initiating events, very few fire zones were found to be applicable because of physical separation criteria. Also, relative to other plants, Grand Gulf utilizes more automatic fire protection systems in critical safety-related areas, which in turn reduces the probability of damage from a fire. Therefore, after taking into account the physical separation of safety-related functions, automatic fire protection systems, lower frequencies of fire-initiated events, and manual fire suppression, most initiating events at shutdown and many fire zones were eliminated from further analysis.

A detailed fire propagation analysis was performed for the remaining initators and respective fire zones. It was found that only in very limited areas could fire damage result in both the initiating event and other fire-related failures that were necessary for core damage. Even in these situations, other random failures (nonfire-related) were also necessary before core damage occurred. Therefore, when taking into account the reduction in fire frequency caused by the limited area of influence and other random failures which were required before core damage, all remaining fire scenarios were found to be less than the truncation limit.

In all areas, additional random failures of equipment (damage not related to the fire itself) had to occur in order to obtain core damage. Adequate separation of equipment (and/or) cabling between redundant functions and the presence of automatic fire suppression systems reduced core damage frequency for those areas.

\section{Insights from Internal Flooding Events}

The overall conclusion of this work is that internal floods do not pose a significant core damage threat to the Grand Gulf Nuclear Station for POS 5 during a refueling outage. The core damage frequency of $2.3 \mathrm{E}-8$ per year resulting from internal flood events is approximately two orders of magnitude lower than the core damage frequency of $2.0 \mathrm{E}-6$ per year for traditional internal events. Thus, internal flooding would make only a minor contribution to the total core damage frequency during POS 5 . This is principally because of the low frequency of fluid boundary component breaks that could result in a flood and a separation of systems that would be available to mitigate the effects of such an accident.

The two conservative assumptions affecting flow rates and flood volumes included in these analyses (i.e., fully guillotined catastrophic breaks and full hour undetected breaks) did not significantly affect the results of this study. For completeness, it should be noted that the assumed undetected break time for the single surviving sequence was 15 minutes. This time, while a departure from the 1-hour assumption, was sufficient to cause a loss of all Class $\mathrm{IE}$ ac and dc power, and probably represents a more realistic estimate of the undetected break time for POS 5 during a refueling outage. 
Insights from Seismic Events

The mean core damage frequency of $7.1 \mathrm{E}-8$ per year (maximum) is also low relative to the $2.0 \mathrm{E}-6$ per year frequency for traditional internal initiators. Two reasons for this are:

1. Grand Gulfs seismic capacity in responding to earthquakes during shutdown is excellent, well above its design basis.

2. The Grand Gulf site is one of the least seismically active locations in the United States.

\subsection{Level 2/3 Results}

\subsubsection{Core Damage Frequency}

For discussion purposes, the core damage scenarios identified in the Level 1 analysis were combined into the following three PDS groups (12 PDSs were actually evaluated in the accident progression analysis): (LOCAs, station blackouts (SBOs), and Other transients. The total core damage frequency and the fractional contributions to the core damage frequency for these three groups are provided in Table 1. The LOCA PDS group is the dominant contributor to the core damage frequency, followed by the SBO PDS group and the Other transients PDS group.

\subsubsection{Accident Progression}

A simplified representation of the accident progression event tree (APET) that addresses the major aspects of the accident is shown in Figure 5. (The actual APET included 59 top events or questions.) Figure 5 combines the results from all the accidents and is conditional on the occurrence of core damage; the values displayed are mean conditional probabilities. From the simplified tree presented in Figure 5, it can be seen that in the most likely accidents in POS 5 the containment is open, the suppression pool is bypassed, and the vessel fails. For the cases where the vessel fails, there is a significant probability that the core debris will either be quenched in a flooded cavity or the interactions between the core debris and the concrete structures beneath the vessel, the core-concrete interaction (CCI), will occur in a flooded cavity. For the cases where the vessel fails, there is a significant probability that the core debris will either be quenched in a flooded cavity or the interactions between the core debris and the concrete structures beneath the vessel, the CCI, will occur in a flooded cavity. For the former, the releases associated with $\mathrm{CCI}$ are prevented. In the latter case, the radioactive releases are scrubbed by the water in the flooded cavity, which helps reduce the source term to the environment. If the containment is closed prior to core damage, it is predicted to either fail or to be vented after core damage because containment heat removal is not available in these accidents. Venting the containment late in the accident is the most likely scenario. For the accidents identified in POS 5, the containment sprays were never available after the onset of core damage.

\subsubsection{Aggregate Risk}

Table 2 presents the offsite risk results for the following six measures: early fatalities, total latent cancer fatalities, population dose within 50 miles of the site, population dose within 1000 miles of the site, individual early fatality risk within 1 mile of the site, and individual latent cancer risk within 10 miles of the site.

Many factors can affect the magnitude and severity of the release and in turn affect risk. Factors associated with POS 5 accidents that tend to increase risk include the following:

- In many of the accidents the containment equipment hatch was open during the entire accident. An open equipment hatch provides a path for radionuclides to escape from the containment to the auxiliary building and then out into the environment.

- Two plant features that can be used to attenuate the release of radioactive aerosols are the suppression pool and the containment sprays. In both the LOCA and the SBO PDSs, the radioactive material released from the damaged fuel bypassed the suppression pool. The containment sprays were not available in any of the POS 5 accidents.

- In many of the accidents, core cooling was not restored early in the accident, thus precluding any possibility of arresting the core damage process before vessel failure. When the vessel fails, the core debris in the vessel is 
Table 1 Core Damage Frequency for POS 5 and Fractional Contributions to the Core Damage Frequency for the LOCA, SBO, and Other Transients Plant Damage State Groups

\begin{tabular}{|c|c|c|c|c|c|}
\hline \multirow{3}{*}{$\begin{array}{l}\text { Plant Damage } \\
\text { State Groups }\end{array}$} & \multicolumn{5}{|c|}{ Descriptive Statistics' } \\
\hline & \multicolumn{3}{|c|}{ Percentiles } & \multirow{2}{*}{ Mean } & \multirow{2}{*}{$\begin{array}{l}\text { Standard } \\
\text { Deviation } \\
\end{array}$} \\
\hline & 5th & 50th & 95th & & \\
\hline \% \%:।. & \multicolumn{4}{|c|}{ 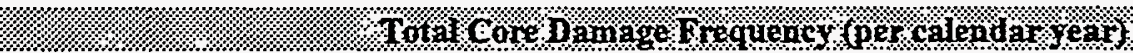 } & \multirow{2}{*}{ 2.7E-06 } \\
\hline Total & $4.1 \mathrm{E}-07$ & $1.4 \mathrm{E}-06$ & $5.6 \mathrm{E}-06$ & 2.1E-06 & \\
\hline \%া \% & \%াষ & \multicolumn{3}{|c|}{ 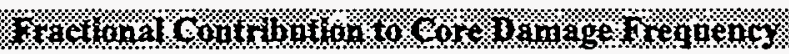 } & ४৷ \\
\hline LOCA & 0.10 & 0.50 & 0.93 & 0.51 & 0.27 \\
\hline SBO & 0.03 & 0.24 & 0.80 & 0.33 & 0.26 \\
\hline Other & 0.01 & 0.09 & 0.58 & 0.17 & 0.18 \\
\hline
\end{tabular}

"Statistics based on a Latin hypercube sampling (LHS) sample size of 200 observations.

Stas of Stusa Sppresion

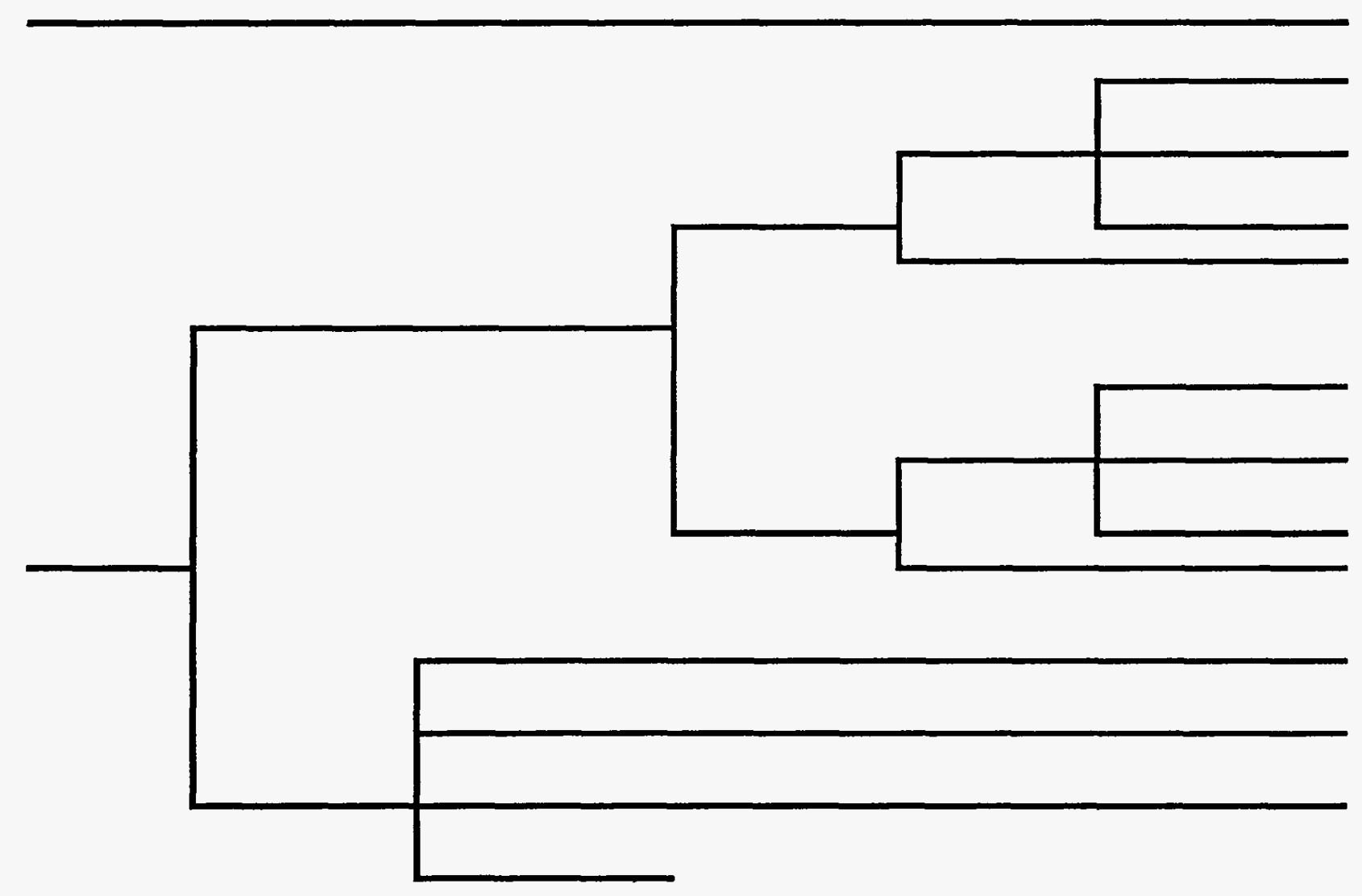

Figure 5 Simplified Representation of POS 5 Accident Progressions 
Table 2 Distributions for Aggregated Risk for POS 5 (all values are per calendar year; population doses are in person-rem)

\begin{tabular}{|c|c|c|c|c|c|}
\hline \multirow{3}{*}{$\begin{array}{c}\text { Consequence } \\
\text { Measures }\end{array}$} & \multicolumn{5}{|c|}{ Descriptive Statistics ${ }^{2}$} \\
\hline & \multicolumn{3}{|c|}{ Percentiles } & \multirow[t]{2}{*}{ Mean } & \multirow{2}{*}{$\begin{array}{l}\text { Standard } \\
\text { Deviation }\end{array}$} \\
\hline & Sth & 50 th & 95th & & \\
\hline Early Fatality Risk & 3.7E-11 & $2.8 \mathrm{E}-09$ & $3.9 \mathrm{E}-08$ & $1.4 \mathrm{E}-08$ & $5.4 \mathrm{E}-08$ \\
\hline Total Latent Cancer Risk & 4.3E-04 & $1.9 \mathrm{E}-03$ & $1.2 \mathrm{E}-02$ & $3.8 \mathrm{E}-03$ & 7.7E-03 \\
\hline Population Dose within 50 miles of the plant & $1.3 \mathrm{E}-01$ & 5.3E-01 & $3.1 \mathrm{E}+00$ & $9.9 \mathrm{E}-01$ & $1.9 \mathrm{E}+00$ \\
\hline Population Dose within 1000 miles of the plant & 9.9E-01 & $4.4 E+00$ & $2.8 \mathrm{E}+01$ & 8.7E+00 & $1.8 \mathrm{E}+01$ \\
\hline Individual Early Fatality Risk- 0 to 1 mile & $4.2 \mathrm{E}-13$ & $2.7 \mathrm{E}-11$ & $3.0 \mathrm{E}-10$ & $9.6 \mathrm{E}-11$ & $3.4 \mathrm{E}-10$ \\
\hline Individual Latent Cancer Risk-- 0 to 10 miles & $2.5 \mathrm{E}-10$ & 9.4E-10 & 4.9E-09 & $1.6 \mathrm{E}-09$ & $2.4 \mathrm{E}-09$ \\
\hline
\end{tabular}

Statistics are based on a LHS sample of 200 observations.

released into the reactor cavity, allowing for possible CCIs. Significant amounts of radioactive material can be released during this ex-vessel phase of the accident.

A number of factors associated with these POS 5 accidents also tend to decrease risk. These factors are listed below:

- Although in many of the accidents the containment equipment hatch is open, the suppression pool is bypassed, and the containment sprays are unavailable, the releases pass through the auxiliary building before escaping into the environment. Because of its large volume and surface area, the auxiliary building provides a location for the radionuclides to be attenuated by deposition and thereby reduce the source term to the environment.

- The accidents delineated for these shutdown conditions progress slowly, and therefore a considerable amount of time is generally available for the public to respond to the accident and evacuate before exposure to the release. This is primarily important for measures of the early health effects, which are more strongly affected by the time available for evacuation.

- Radioactive decay has reduced the radioactive potential of these shutdown accidents relative to the inventory that is present immediately after the reactor is shut down. This factor is primarily important for early health effects, which are more strongly affected by the shorter lived radionuclides. This effect is much less noticeable for latent health effects, which are more strongly affected by the longer lived isotopes.

- The population around the Grand Gulf plant is relatively low. Although many factors influence the magnitude of the consequences, in general, for a given release, a smaller population correlates with a smaller number of fatalities. Of the four Mark III plants in the United States, Grand Gulf has the fewest number of people living within 50 miles of the plant, according to the 1990 census data. The Mark III plant with the greatest number of people living within 50 miles of the site has a population that is more than an order of magnitude greater than the Grand Gulf 50-mile population.

To place the risks from POS 5 into context, they were compared with the risks from full power operation as estimated in the NUREG-1150 Grand Gulf plant analysis. ${ }^{[7]}$ In Figure 6, the early fatality and total latent cancer fatality risks from full power operation and POS 5 are presented. This comparison shows that the risks from POS 5 are not insignificant compared with the risks from full power operation. In fact, although the mean risk values from the two studies are similar (i.e., not differing by more that a factor of 5), the mean risk values from POS 5 are actually greater than the full power risk values.

Table 3 provides the fractional contributions to the early fatality risk and the total latent cancer risk for the following three PDS groups: LOCAs, SBOs, and Other transients. The fractional contributions to the population dose risk measures (not shown in Table 3 for brevity) are similar to the fractional contributions to the total latent cancer risk measure. From Table 3 it can be seen that, on average, the SBO PDS group is the dominant contributor to the total early fatality risk. Because a large amount of overlap exists among the three distributions, as is evident from the descriptive 


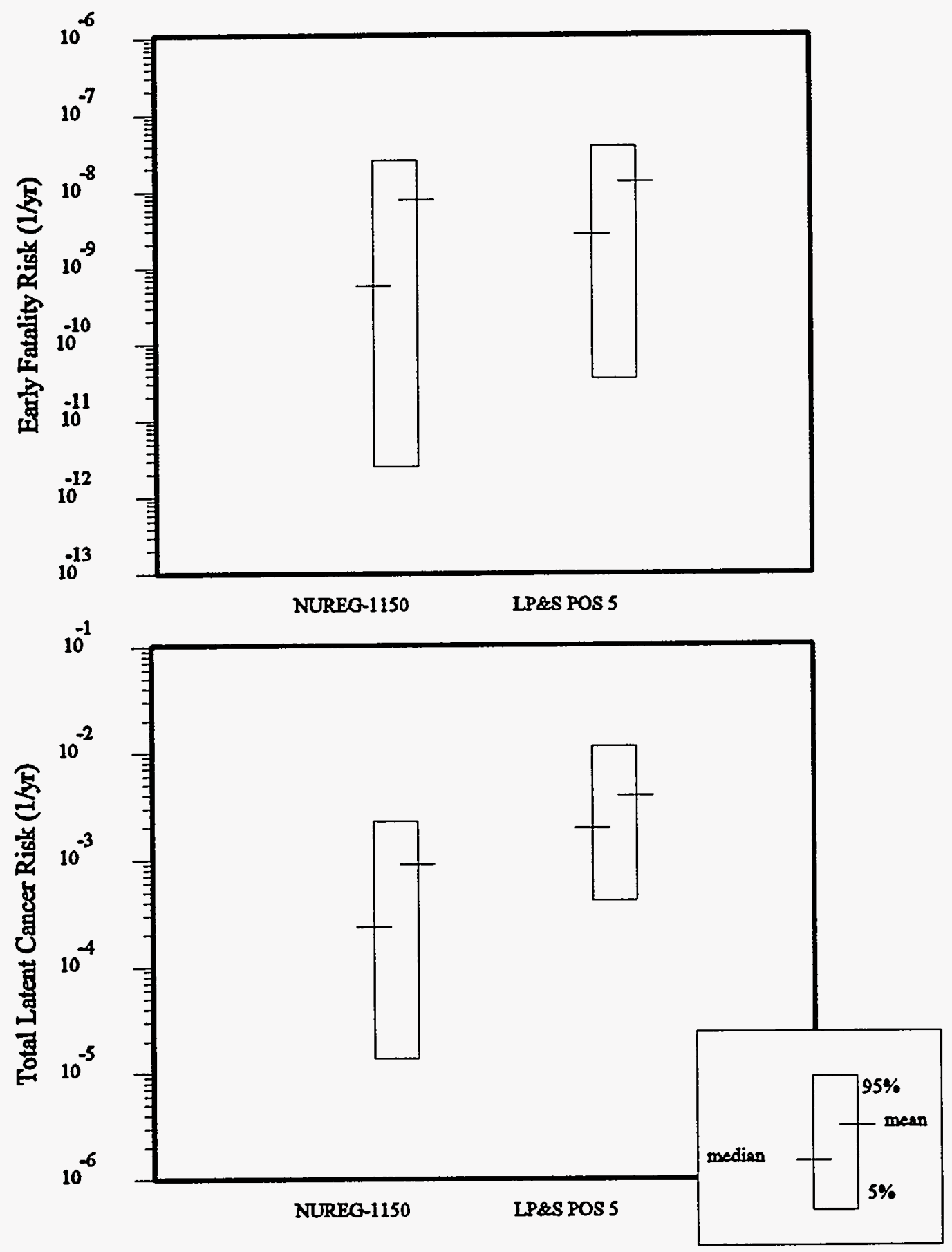

Figure 6

Comparison of POS 5 Risk with Full Power Risk 
Table 3

Fractional Contributions to Aggregate Risk for the LOCA, SBO, and Other Transients Plant Damage State Groups

\begin{tabular}{|c|c|c|c|c|c|}
\hline \multirow{3}{*}{$\begin{array}{l}\text { Plant Damage } \\
\text { State Groups }\end{array}$} & \multicolumn{5}{|c|}{ Descriptive Statistics" } \\
\hline & \multicolumn{3}{|c|}{ Percentiles } & \multirow[t]{2}{*}{ Mean } & \multirow{2}{*}{$\begin{array}{l}\text { Standard } \\
\text { Deviation }\end{array}$} \\
\hline & 5th & 50th & 95th & & \\
\hline 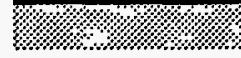 & \%1: & \multicolumn{3}{|c|}{ 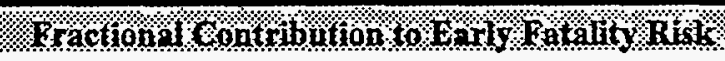 } & $1.1 \%$ \\
\hline LOCA & 0.001 & 0.04 & 0.72 & 0.16 & 0.24 \\
\hline SBO & 0.080 & 0.87 & 1.00 & 0.73 & 0.30 \\
\hline \multirow[t]{2}{*}{ Other } & 0.001 & 0.04 & 0.61 & 0.12 & 0.18 \\
\hline & \multicolumn{4}{|c|}{ 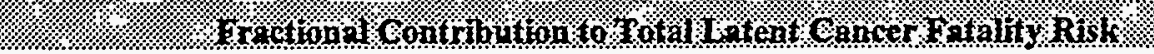 } & \%: \\
\hline LOCA & 0.04 & 0.38 & 0.90 & 0.42 & 0.27 \\
\hline SBO & 0.04 & 0.41 & 0.90 & 0.45 & 0.28 \\
\hline Other & 0.01 & 0.06 & 0.55 & 0.13 & 0.17 \\
\hline
\end{tabular}

Statistics are based on a LHS sample of 200 observations.

statistics provided in Table 3, on any given observation (an observation is one particular trial in the many trials made in a Monte Carlo type analysis) the contribution from the three groups can vary. That is, for one observation the SBO group may be dominant, whereas for another observation the LOCA group may be the dominant group. On average, however, the SBO is the dominant contributor. The SBO PDS group's large contribution to early fatality risk can be attributed to its relatively high contribution to the core damage frequency coupled with the fact that the containment equipment hatch is open, the suppression pool is bypassed, and the auxiliary building fails early in these accidents.

Combined, these factors cause the SBOs to have relatively high risk values. The LOCA PDS group, however, is not a dominant contributor to early fatality risk even though it is a dominant contributor to the core damage frequency. This situation occurs primarily because the dominant contributors to the LOCA core damage frequency are LOCA accidents that are initiated while the plant is in time window 3 (i.e., PDS3-1). Numerous factors can reduce the number of early fatalities that occur when the accident is initiated in time window 3 relative to the other time windows. These factors include the following conditions: (1) Radioactive decay has reduced the inventory of short-lived radionuclides that are important to early health effects. (2) Because of the lower decay heat, the accidents progress more slowly, allowing more time for the population to evacuate. (3) The release is spread out over a longer time which helps reduce the concentration of radionuclides in the environment. For these reasons time window 3 is a negligible contributor to early fatality risk.

For latent cancer health effects, the LOCA and SBO PDS groups are, on average, the dominant contributors to risk. Because the radionuclides that are important to the latent health effects tend to have long half lives, these risk measures are not particularly sensitive to the time of accident occurrence relative to shutdown . Latent cancers primarily depend on the total amount of radioactive material released, not on the time it was released (i.e., early in the accident versus late in the accident). Because latent cancers are not strongly dependent on the timing characteristics of the accident (i.e., start of release or release duration), the latent cancer risk will depend on the likelihood of the accident and on the total amount of radioactive material released. In all of the core damage accidents delineated in this study, the containment is either open at the start of the accident or fails during the accident, and in most of the accidents the core damage process is not arrested in the vessel. Thus, although the timing of the accident may vary, when the uncertainty in the source term is considered, all the accidents will result in roughly similar releases of radioactive material to the environment. Thus, as can be seen in Tables 1 and 3, the mean fractional contribution to latent cancer risks tends to be roughly similar to the mean fractional contribution to the core damage frequency for each of the PDS groups. The fractional contributions from the LOCA and Other transient groups tend to be less than their fractional contributions to the core damage frequency because for these PDSs, portions of the release are scrubbed by either the suppression pool or the pool formed by flooding the containment. The fractional contribution from the SBO PDS group tends to be greater than the fractional contribution to the core damage frequency because for these accidents the containment is open at the start of the accident, the auxiliary building fails early in the accident, the vessel always fails, $\mathrm{CCI}$ always occurs, and none of the releases are scrubbed by water. Therefore the releases associated with the SBO tend to be large relative to the other accidents analyzed in this study. 


\subsubsection{Qualitative Issues and Cautions}

The results presented here for the Level $2 / 3$ analysis are for a single POS (namely POS 5) and, as such, only assess the risk associated with this POS. While the Phase 1 screening study and other qualitative insights suggest that POS 5 is the risk-dominant mode of shutdown, no detailed study has been performed on the other POSs to confirm this belief.

Only accidents initiated from traditional internal events were analyzed in this study. Hence, the risk calculated for POS 5 is not complete in the sense that it does not include accidents initiated by internal fires and floods; it also does not include accidents initiated by seismic events.

It is important to realize that reducing the risk in one POS, for example by changing when equipment is available and unavailable, can shift the risk to another POS. Since this study only addresses the risk associated with one POS, the effect of this change on overall risk (i.e., risk across all the POSs) cannot currently be quantitatively assessed.

Since only a single plant was analyzed, these results cannot be considered generic and applicable to a population of plants. The plant and system models used in this study are based on the Grand Gulf plant as it operates in a selected mode of operation. Thus, while some insights may be applicable to other plants, in general, the results from this study should not be arbitrarily applied to other plants or conditions. The model used to develop the progression of the accidents after the onset of core damage is, in part, based on the Grand Gulf Emergency Operating Procedures and other procedures and practices at the plant. Changes in these procedures and practices can certainly affect the progression of the accident and the ultimate risk of the POS. Similarly, since the offsite consequences are sensitive to the site characteristics and surrounding region (e.g., weather, population, land use), for a given release of radioactive material, the consequences can be expected to vary from one site to the next.

\subsection{General Conclusions}

\subsubsection{Level 1 Conclusions}

The conclusions drawn from the Level 1 study can be grouped into three categories. They are (1) methodological, (2) plant specific, and (3) generic.

\section{Methodological}

This study was successful in developing a methodology to estimate the risk (i.e., the core damage frequency) associated with the operation of a BWR during low power and shutdown conditions. The methodology developed and the lessons learned from its application provide the NRC with new tools that could be used in subsequent analyses.

The mean CDF for each of the internal and external analyses presented in this report includes the fraction of time the plant is in POS 5 during a refueling outage. If one wanted to present the results as a conditional CDF (i.e., conditional on the plant being in POS 5), then the results should be divided by the value assigned to the POS 5 event. Thus, for example, for the total plant model for the traditional internal events analysis, the conditional CDF is $(2 \mathrm{E}-6) / 0.031=$ $6.5 \mathrm{E}-5$ per year in POS 5. However, use of the conditional CDF on a per year basis is not recommended since plant conditions (e.g., system unavailabilities and decay heat loads) would change dramatically during a year. However, it does show that the instantaneous CDF is higher in POS 5 than at full power.

\section{Plant Specific}

There are three major aspects of the specific Grand Gulf plant model used in this analysis that significantly affected the results. These are

1. Grand Gulfs continued requirement for automatic isolation of low-pressure components in the shutdown cooling system, given an increase in pressure and/or a decrease in water level in POS 5.

2. Grand Gulf's requirement that at least two safety relief valves be available in POS 5 allows the operators to use portions of their inadequate decay heat removal procedure, which would otherwise be inaccessible.

3. Grand Gulf's additional system for removing decay heat (i.e., the alternate decay heat removal system) affects the estimated core damage frequency during two of the three POS 5 time windows. 


\section{Generic}

The results from this study appear to indicate that the core damage frequency associated with operating in POS 5 during a refueling outage is less than that from operating at full power. While this should be true for Grand Gulf, generalizations to other BWRs should be performed with care.

Two factors that should be considered during any generalization are

1. Does the other BWR have a motor-driven high-pressure pump? The availability of such a pump provides a mechanism for injecting water at high pressure, if necessary, and also provides an alternative means of injecting water at low pressure should the low-pressure pumps fail.

2. Does the other BWR have procedures in place to deal with the loss of the normal decay heat removal system? If the procedures do exist, does the utility require that the systems and components necessary for the procedure be available?

\subsubsection{Level 2/3 Conclusions}

The following conclusions can be drawn from this study:

- With many plant features unavailable to mitigate a release, the potential exists for a large release of radioactive material should core damage occur. For the most likely accidents, the containment is open, the suppression pool is bypassed, and the containment sprays are not available.

- In the event that the containment is closed prior to the onset of core damage, it is always predicted to fail since containment heat removal was not available in the accidents analyzed.

- The risks from POS 5 are not insignificant compared with the risks from full power operation. Hence the full-power risk distributions by themselves do not completely characterize the risks associated with the operation of this plant. To accurately characterize the plant results from this study, it may be necessary to include other modes of operation in addition to the full-power mode. This can have important implications for assessments that rely on the total risk from a plant, such as when comparisons are made with the safety goals.

- Although only a simplified scoping study of the onsite consequences was performed, the possible consequences of an accident during shutdown could be significant, particularly since in many of the accidents the containment remains open, allowing an early release of radioactive material.

\section{Surry Results and Conclusions}

The results and conclusions presented below come directly from NUREG/CR-6144, Vols. 2 - 6..$^{[8-13]}$

\subsection{Level 1 Results}

\subsubsection{Results from Traditional Internal Events}

Table 4 summarizes the results of the event tree quantification, showing the core damage frequency as a function of the initiating events and POSs. The core damage frequency is the frequency that core damage occurs while the reactor is at midloop, and includes the fraction of a year that the reactor is at midloop. POS 6 of a drained maintenance outage (D6), and POS 6 of a refueling outage (R6) are the most dominant POSs. Their characteristics are high decay-heat level and a relatively short time available for operator action. In contrast, POS 10 of a refueling outage (R10) has a very low decay heat, and its core damage frequency is approximately one order of magnitude lower.

Table 5 compares the results of this study with those of NUREG-1150 ${ }^{[14]}$ and the individual plant examination ${ }^{[13]}$ performed by the utility for Surry. The results are displayed in two ways. The core damage frequency, shown in the first row, is the frequency with which core damage occurs when the plant is at midloop (the core damage frequencies in the parentheses are the contributions from overdraining events), and the conditional core damage frequency, shown in the third row, is the core damage frequency (minus the contribution of overdraining events) divided by the fraction of time the plant is at midloop. The former accounts for the fact that the plant is at midloop only a small fraction of the time, while the latter is the conditional frequency at which core damage occurs given the plant is at midloop. The core 
Table 4 Summary of Results-Core Damage Frequency by Initiating Event and Plant Operational States

\begin{tabular}{||l|l|c|c|c|c||}
\hline \multicolumn{1}{|c|}{ Initiating Event } & \multicolumn{3}{c|}{ Core Damage Frequency (per year) } \\
\hline \hline 1. & Loss of residual heat removal (RHR) & R6 & R10 & D6 & Total \\
\hline & RHR2A-Over Draining & $1.8 \mathrm{E}-7$ & $5.3 \mathrm{E}-8$ & $2.6 \mathrm{E}-7$ & $4.9 \mathrm{E}-7$ \\
\hline & RHR2B-Failure to Maintain Level & $2.1 \mathrm{E}-8$ & $2.0 \mathrm{E}-8$ & $2.9 \mathrm{E}-8$ & $7.0 \mathrm{E}-8$ \\
\hline & RHR3-Nonrecoverable Loss of RHR & $1.5 \mathrm{E}-7$ & $8.4 \mathrm{E}-9$ & $3.0 \mathrm{E}-7$ & $4.6 \mathrm{E}-7$ \\
\hline & RHR4-Nonrecoverable Loss of Operating Train of RHR & $7.6 \mathrm{E}-9$ & $1.2 \mathrm{E}-9$ & $2.3 \mathrm{E}-8$ & $3.2 \mathrm{E}-8$ \\
\hline & RHRS-Recoverable Loss of RHR & $4.0 \mathrm{E}-8$ & $4.1 \mathrm{E}-9$ & $9.3 \mathrm{E}-8$ & $1.4 \mathrm{E}-7$ \\
\hline 2. & LOOP-Loss of Offsite Power & & & & \\
\hline & L1-Both 1H and 1J Energized & $3.3 \mathrm{E}-7$ & $7.0 \mathrm{E}-8$ & $7.6 \mathrm{E}-7$ & $1.2 \mathrm{E}-6$ \\
\hline & L2-1H and 2H energized, not 1J & $1.0 \mathrm{E}-7$ & $1.3 \mathrm{E}-8$ & $1.7 \mathrm{E}-7$ & $2.9 \mathrm{E}-7$ \\
\hline & L3-1H energized, not 1J, unit 2 blackout & $4.2 \mathrm{E}-8$ & $1.3 \mathrm{E}-8$ & $9.9 \mathrm{E}-8$ & $1.5 \mathrm{E}-7$ \\
\hline & B1-Unit 1 Blackout & $4.8 \mathrm{E}-8$ & $1.1 \mathrm{E}-8$ & $1.7 \mathrm{E}-7$ & $2.3 \mathrm{E}-7$ \\
\hline & B2-2 Unit Blackout & $3.8 \mathrm{E}-8$ & $4.2 \mathrm{E}-8$ & $1.1 \mathrm{E}-7$ & $1.9 \mathrm{E}-7$ \\
\hline 3. & 4kV-Loss of 4kV Bus & $1.4 \mathrm{E}-7$ & $1.9 \mathrm{E}-8$ & $2.4 \mathrm{E}-7$ & $4.0 \mathrm{E}-7$ \\
\hline 4. & VITAL-Loss of Vital Bus & $2.8 \mathrm{E}-8$ & $5.1 \mathrm{E}-9$ & $7.3 \mathrm{E}-8$ & $1.1 \mathrm{E}-7$ \\
\hline 5. & AIR-Loss of Outside Instrument Air & $7.9 \mathrm{E}-10$ & - & $3.2-9$ & $4.0 \mathrm{E}-9$ \\
\hline 6. & CCW-Loss of CCW & $6.3 \mathrm{E}-8$ & $1.1 \mathrm{E}-10$ & $2.1 \mathrm{E}-7$ & $2.7 \mathrm{E}-7$ \\
\hline 7. & SWGR-Loss of Emergency Switchgear Room Cooling & $3.6 \mathrm{E}-8$ & $1.2 \mathrm{E}-8$ & $7.4 \mathrm{E}-8$ & $1.2 \mathrm{E}-7$ \\
\hline 8. & ESFAS-Inadvertent Safety Feature Actuation & $2.7 \mathrm{E}-7$ & $2.7 \mathrm{E}-8$ & $6.8 \mathrm{E}-7$ & $9.8 \mathrm{E}-7$ \\
\hline 9. & Dilute-Boron Dilution (CDF) & - & - & - & $6.8 \mathrm{E}-8$ \\
\hline \hline TOTAL & & $1.5 \mathrm{E}-6$ & $3.0 \mathrm{E}-7$ & $3.3 \mathrm{E}-6$ & $5.1 \mathrm{E}-62$ \\
\hline
\end{tabular}

Not including boron dilution.

Table 5 Comparison of Total Core-Damage Frequency with NUREG-1150 and IPE

\begin{tabular}{|c|c|c|c|c|c|}
\hline Study & \multicolumn{5}{|c|}{ Results } \\
\hline \multirow{4}{*}{$\begin{array}{l}\text { PWR Low Power and } \\
\text { Shutdown Study (Midloop } \\
\text { POSs, Internal Event Only) }\end{array}$} & & R6 & $\mathrm{R} 10$ & D6 & TOTAL \\
\hline & $\mathrm{CDF}^{2}$ per year & $\begin{array}{c}1.49 \mathrm{E}-6 \\
(1.82 \mathrm{E}-7)^{b}\end{array}$ & $\begin{array}{c}3.06 \mathrm{E}-7 \\
(5.47 \mathrm{E}-8)^{\mathrm{b}}\end{array}$ & $\begin{array}{c}3.25 \mathrm{E}-6 \\
(2.67 \mathrm{E}-7)^{\mathrm{b}}\end{array}$ & $\begin{array}{c}5.06 \mathrm{E}-6 \\
(5.04 \mathrm{E}-7)^{\mathrm{b}}\end{array}$ \\
\hline & $\begin{array}{l}\text { Fraction of a year the plant } \\
\text { is in midloop }\end{array}$ & $1.63 \mathrm{E}-2$ & $1.52 \mathrm{E}-2$ & $3.49 \mathrm{E}-2$ & $6.64 \mathrm{E}-2$ \\
\hline & $\begin{array}{c}\text { Conditional CDF per year } \\
\text { (CDP) }\end{array}$ & $\begin{array}{c}8.09 \mathrm{E}-5 \\
(3.03 \mathrm{E}-7) \\
\end{array}$ & $\begin{array}{r}1.65 \mathrm{E}-5 \\
(1.82 \mathrm{E}-7) \\
\end{array}$ & $\begin{array}{r}8.55 \mathrm{E}-5 \\
(2.23 \mathrm{E}-7) \\
\end{array}$ & $\begin{array}{r}7.62 \mathrm{E}-5 \\
(2.40 \mathrm{E}-7) \\
\end{array}$ \\
\hline $\begin{array}{l}\text { NUREG-1150 (Internal } \\
\text { Event Only) }\end{array}$ & \multicolumn{5}{|c|}{$4.01 \mathrm{E}-5$} \\
\hline IPE (Internal Event Only) & \multicolumn{5}{|c|}{$7.40 \mathrm{E}-5$} \\
\hline
\end{tabular}

- CDF reflects the fraction of time the plant is at midloop.

b Contribution of overdraining events.

c Frequency of core damage given that the plant is at midloop.

$\mathrm{CDP}=$ probability of core damage resulting from overdraining to the POS 
damage frequency of midloop operations is approximately one eighth of that of power operation as estimated in NUREG-1150, while the plant is in midloop operation approximately 7 percent of a year. The numbers in the parentheses of the third row of the table are the conditional probability of core damage from overdraining events, given that the plant enters midloop operation in the POS.

The core damage frequencies shown in the first row of Table 5 are additive. That is, the sum of the core damage frequencies of the 3 POSs is the total core damage frequency of midloop operation. This total, 5.06 E-06 per year, can be added to the core damage frequency of power operation, e.g., 4.01 E-05 per year for NUREG-1150. Therefore, the sum of 4.51 E-05 per year is the frequency per year that core damage occurs while the plant is at full power or mid-loop operation.

The conditional core damage frequency shown in the third row of Table 5 is a measure of how susceptible a plant configuration is with respect to core damage. For example, the fact that the conditional core-damage frequency of midloop operation, 7.62 E-05 per year, is higher than that of full power operation, $4.01 \mathrm{E}-05$ per year, shows that midloop operation is more susceptible to core damage than full power operation, although the plant is at midloop only a small fraction of the time.

Table 6 lists the conditional core damage frequency as a function of the time windows and POSs. The conditional core damage frequency is the rate at which core damage occurs given that the plant is in the time window of the POS. It is obtained by dividing the core damage frequency by the fraction of time the plant is in the time window of the POS. The conditional core damage frequency/probability is a measure that can be used to compare the vulnerability of the time windows and POSs with respect to core damage. It can be seen from Table 6 that for each POS the conditional core damage frequency decreases with the time window. This is due to the relaxed success criteria and more time available for operator actions. The conditional core damage frequency/probability for R6 or R10 is higher than that of D6 mainly because the RCS loops have a high probability of being isolated in a refueling outage; that makes reflux cooling impossible. For example, in window 1, the probability that the loops are isolated in a refueling outage is 0.3 , and the probability that reflux cooling fails in a drained maintenance outage is 0.1 (modeled as a recovery action). The difference between R6 and R10 in windows 3 and 4 is due to the difference in maintenance unavailabilities.

Table 6 Conditional Core Damage Frequency As a Function of the Time Windows and POSs (per year)

\begin{tabular}{||l|c|c|c|c||}
\hline & R6 & R10 & D6 & Total \\
\hline Window 1 $(13 \mathrm{hr}-75 \mathrm{hr})$ & $9.96 \mathrm{E}-4$ & - & $3.37 \mathrm{E}-4$ & $3.77 \mathrm{E}-4$ \\
\hline Window 2 $(75 \mathrm{hr}-240 \mathrm{hr})$ & $7.55 \mathrm{E}-5$ & - & $5.90 \mathrm{E}-5$ & $7.25 \mathrm{E}-5$ \\
\hline Window 3 $(240 \mathrm{hr}-768 \mathrm{hr})$ & $5.49 \mathrm{E}-5$ & $6.54 \mathrm{E}-5$ & $5.18 \mathrm{E}-5$ & $5.60 \mathrm{E}-5$ \\
\hline Window 4 $(>768 \mathrm{hr})$ & $1.87 \mathrm{E}-5$ & $1.57 \mathrm{E}-5$ & $1.05 \mathrm{E}-5$ & $1.80 \mathrm{E}-5$ \\
\hline TOTAL & $8.09 \mathrm{E}-5$ & $1.65 \mathrm{E}-5$ & $8.55 \mathrm{E}-5$ & $7.62 \mathrm{E}-5$ \\
\hline
\end{tabular}

The total and subtotals in Table 6 represent the averaged conditional core damage frequency. For example, the averaged conditional core damage frequency for R6 is $8.09 \mathrm{E}-05$ per year, while that for D6 is $8.55 \mathrm{E}-05$ per year. This means that the plant is better off if it is in R6, given it is at midloop. This does not contradict the comparison made earlier for a given time window of the POSs, because given that plant is in D6, it is more likely to be in the earlier time windows that have higher conditional core damage frequency. The averaged conditional core damage frequency over the POSs, shown in the rightmost column of Table 6 , does show a trend of decreasing with decay heat. The reversed trend for the averaged conditional core damage probability for windows 3 and 4 is caused by the same error introduced by truncation that made the trend reversed for the conditional core damage probability of R10 in windows 3 and 4.

Table 7 lists the key uncertainty characteristics of the core-damage frequencies for midloop operation and power operation, and shows that the core damage for midloop operation has a wider spread than that of power operation. Note also that the mean total CDF in Table 7 is slightly different for the total CDF in Tables 4 and 5 . This is because the numbers in Tables 4 and 5 are point estimates whereas the information in Table 7 reflects an uncertainty analysis. 
Table 7 Result of the Level 1 Uncertainty Analysis and Comparison with Full Power Operation (per year)

\begin{tabular}{|c|c|c|c|c|c|c|c|}
\hline & \multicolumn{2}{|l|}{ Study } & Mean & $\begin{array}{c}\text { 5th } \\
\text { Percentile }\end{array}$ & $\begin{array}{c}\text { 50th } \\
\text { Percentile }\end{array}$ & $\begin{array}{c}\text { 95th } \\
\text { Percentile }\end{array}$ & $\begin{array}{l}\text { Error } \\
\text { Factor }\end{array}$ \\
\hline \multirow[t]{3}{*}{$\begin{array}{l}\text { Internal } \\
\text { Events }\end{array}$} & \multicolumn{2}{|c|}{$\begin{array}{l}\text { Full Power Operation - NUREG } 1150 \\
\text { (per year) }\end{array}$} & $4.01 \mathrm{E}-5$ & $6.75 \mathrm{E}-6$ & $2.31 E-5$ & $1.31 \mathrm{E}-4$ & 4.41 \\
\hline & \multicolumn{2}{|c|}{ Full Power Operation-IPE } & $7.40 \mathrm{E}-5^{2}$ & - & - & - & - \\
\hline & \multicolumn{2}{|c|}{$\begin{array}{l}\text { Midloop Operation (per year while at } \\
\text { midloop) }\end{array}$} & $4.86 \mathrm{E}-6$ & $4.76 \mathrm{E}-7$ & $2.14 \mathrm{E}-6$ & $1.54 \mathrm{E}-5$ & 5.69 \\
\hline \multirow[t]{3}{*}{$\begin{array}{l}\text { Internal } \\
\text { Fires }\end{array}$} & \multicolumn{2}{|c|}{$\begin{array}{l}\text { Full Power Operation - NUREG } 1150 \\
\text { (per year) }\end{array}$} & $1.13 \mathrm{E}-5$ & - & - & - & - \\
\hline & \multicolumn{2}{|c|}{ Full Power Operation- IPE } & b & - & $=$ & - & - \\
\hline & \multicolumn{2}{|c|}{$\begin{array}{l}\text { Midloop Operation (per year while at } \\
\text { midloop) }\end{array}$} & $2.2 \mathrm{E}-5$ & $1.4 \mathrm{E}-6$ & $9.1 \mathrm{E}-6$ & $7.6 \mathrm{E}-5$ & 7.2 \\
\hline \multirow[t]{3}{*}{$\begin{array}{l}\text { Internal } \\
\text { Flood }\end{array}$} & \multicolumn{2}{|c|}{$\begin{array}{l}\text { Full Power Operation - NUREG } 1150 \\
\text { (per year) }\end{array}$} & c & - & - & - & - \\
\hline & \multicolumn{2}{|c|}{ Full Power Operation- IPE } & $5.0 \mathrm{E} 05^{\mathrm{b}}$ & - & - & - & - \\
\hline & \multicolumn{2}{|c|}{$\begin{array}{l}\text { Midloop Operation (per year while at } \\
\text { midloop) }\end{array}$} & $4.8 \mathrm{E}-6$ & $2.2 \mathrm{E}-7$ & $1.7 \mathrm{E}-6$ & $1.8 \mathrm{E}-5$ & 9.0 \\
\hline \multirow{5}{*}{$\begin{array}{l}\text { Seismic } \\
\text { Events }\end{array}$} & \multirow{2}{*}{$\begin{array}{l}\text { Full Power Operation - } \\
\text { NUREG } 1150 \text { (per year) }\end{array}$} & LLNL & $1.2 \mathrm{E}-4$ & $=$ & - & - & 33 \\
\hline & & EPRI & $4.01 E-5$ & - & - & - & 4.41 \\
\hline & \multicolumn{2}{|l|}{ Full Power Operation-IPE } & & - & - & - & - \\
\hline & \multirow{2}{*}{$\begin{array}{l}\text { Midloop Operation (per year } \\
\text { while at midloop) }\end{array}$} & LLNL & $3.5 \mathrm{E}-7$ & $1.3 \mathrm{E}-9$ & 4.0E-8 & $1.4 \mathrm{E}-6$ & 32 \\
\hline & & EPRI & $8.6 \mathrm{E}-7$ & $2.5 \mathrm{E}-10$ & $9.7 \mathrm{E}-9$ & $3.7 \mathrm{E}-7$ & 37 \\
\hline
\end{tabular}

\subsubsection{Results from Internal Fire Analysis}

Table 8 summarizes the point estimate results of the fire analysis. Note that the CDF is the frequency at which core damage occurs when the plant is at midloop. It accounts for the fact that the plant is at midloop only a small fraction of the time. The quantification indicates that certain scenarios in the $\mathrm{H}$ and $\mathrm{J}$ compartments of the emergency switchgear room, one scenario in the cable vault and tunnel, and one containment scenario dominate the CDF. The most dominant scenarios occur in the cable vault and tunnel (owing to the proximity of many emergency cables from both divisions in a closed, constrained space) and in the J room of the ESGR, where many emergency cables from both the $H$ and the $J$ divisions come together in close proximity (before entering the control room). In the containment, the relatively high CDF is due to a relatively high scenario frequency combined with nonseparation of RHR trains over significant distances. Other scenarios are also important, owing to moderate damage from the fire combined with a relatively high scenario frequency.

POSs D6 and R6 are much more important than R10 (as R10 occurs in later time windows). D6 is more important than R6 owing to constraints imposed by a drained maintenance outage and its tendency to occur in earlier time windows.

The earlier time windows are more important than the later ones, with window 4 being relatively unimportant. Windows 1 and 2 are of the highest importance, with window 2 being significantly more important than window 1 . While the decay heat is higher and the success criteria are more stringent in window 1 , this window doesn't last as long and the outages tend to occur in the later time windows. The most risk significant fire initiator occurs in the cable vault tunnel area, in window 2 and POS D6, followed by a few scenarios in the J room of the ESGR, in the same window and POS. 
Table 8 Summary of Point Estimate Core Damage Frequencies for Fire Events (per year)

\begin{tabular}{||l|c|c|c|c||}
\hline \multicolumn{1}{|c|}{ Fire Area } & R6 & D6 & R10 & Total \\
\hline \hline Emergency Switchgear Room & $4.1 \mathrm{E}-6$ & $8.2 \mathrm{E}-6$ & $2.1 \mathrm{E}-7$ & $1.3 \mathrm{E}-5$ \\
\hline Containment & $7.0 \mathrm{E}-8$ & $5.5 \mathrm{E}-7$ & $5.0 \mathrm{E}-9$ & $6.3 \mathrm{E}-7$ \\
\hline Cable Vault and Tunnel & $1.3 \mathrm{E}-6$ & $2.7 \mathrm{E}-6$ & $7.4 \mathrm{E}-8$ & $4.0 \mathrm{E}-6$ \\
\hline Normal Switchgear Room & $1.5 \mathrm{E}-8$ & $3.5 \mathrm{E}-8$ & $1.4 \mathrm{E}-9$ & $5.1 \mathrm{E}-8$ \\
\hline Main Control Room & $7.0 \mathrm{E}-8$ & $5.3 \mathrm{E}-7$ & $4.4 \mathrm{E}-9$ & $6.0 \mathrm{E}-7$ \\
\hline Total & $5.5 \mathrm{E}-6$ & $1.2 \mathrm{E}-5$ & $2.9 \mathrm{E}-7$ & $1.8 \mathrm{E}-5$ \\
\hline
\end{tabular}

Table 7 summarizes the result of the uncertainty analysis for core damage accidents initiated by fires. The results were obtained by performing uncertainty analysis using 500 Latin hypercube sampling (LHS) samples. Also shown in the table are the uncertainty analysis results of the internal event analysis as well as the mean value of the internal fire analysis of NUREG-1150.

No prevalence of fires at shutdown base was noticed in the data, compared with power operation fires (after the construction events are taken out). It is true that there is greater potential for fires in certain categories (e.g., transient fires, fires caused by welding igniting cables, or other equipment fires). It is also true that the possibility of some types of fires is reduced (e.g. deenergized equipment, oil dripping on hot piping). A fire at shutdown is liable to be detected much sooner and extinguished in its early phases because of increased floor traffic. [Credit is taken for this by disallowing events that were discovered in the smoking stage (without flames) or early enough so that deenergizing equipment extinguished the fire.] Increased vigilance by licensees may play a part in this also. At Surry, a fire watch is in place during welding operations; fire doors are kept closed.

Human error events are not prominent contributors individually in terms of the Fussell-Vesely importance range (a few percent). Part of the reason is that there are many human error probabilities (HEPs), each applicable in a small fraction of sequences; another reason is in the values assigned to the HEPs; the third is that in many important scenarios hardware failures dominate because of heavy damage by fire.

Table 7 provides a comparison of the fire-induced core damage frequency during midloop operation with that of power operation. Although the plant spends much less time in midloop, the core damage frequency is comparable to that of power operation. The main reason is that the routing of the cables of the equipment needed to support RHR operation or mitigate an accident during midloop operation is such that a single fire at a few critical locations can damage almost all the equipment needed, while during power operation there are fewer critical locations.

\subsubsection{Results from Internal Flood Analysis}

The main results of the flooding analysis are presented in Table 9 , which lists the point estimate core damage frequencies of the operating states analyzed. It was found that the most dominant contributors to core damage from internal floods are accident scenarios initiated in the turbine building leading to the draining of the intake canal. This could result in a flood of the plant emergency switchgear rooms (ESGR), leading to a two-unit loss of all emergency power (F1 and F2 scenarios). The scenarios account for approximately 85 percent of the total CDF caused by internal floods. This result is mainly due to the specific features of the Surry circulating water system and may not be applicable to other plants. The second most dominating flood scenario involves flooding of the safeguard/auxiliary building in combination with the unavailability of the refueling water storage tank (RWST). The contribution of these scenarios (F4 and F5) is approximately 13 percent of the total internal CDF. Again, these specific findings may not be generalized to other plants because of the plant-specific nature of the actual evolvement of these accident scenarios.

The main results of the uncertainty analysis are shown in Table 7 and indicate the uncertainty bounds of the core damage frequency caused by internal floods. The important measures of the uncertainty distribution are the 5 th percentile, mean, and 95 th percentile values at $2.2 \mathrm{E}-07,4.8 \mathrm{E}-06$ and $1.8 \mathrm{E}-05 / \mathrm{yr}$, respectively.

The internal flood CDF is dominated by turbine building flood events. These events are primarily initiated by failure of either valves or expansion joints in the main inlet lines of the circulating water system. These failures may lead to pipe 
Table 9 Summary of Point Estimate Core Damage Frequencies for Flood Events (/yr)

\begin{tabular}{||c|c|c|c|c||}
\hline \multirow{2}{*}{ Scenario } & \multicolumn{4}{|c|}{$\begin{array}{c}\text { Core Damage Frequency } \\
\text { w/ Recovery }\end{array}$} \\
\cline { 2 - 5 } & $\begin{array}{c}\text { POS 6 } \\
\text { Refueling }\end{array}$ & $\begin{array}{c}\text { POS 6 } \\
\text { Drained }\end{array}$ & $\begin{array}{c}\text { POS 10 } \\
\text { Refueling }\end{array}$ & Total \\
\hline Turbine Building (F1) & $1.9 \mathrm{E}-6$ & $9.3 \mathrm{E}-8$ & $1.5 \mathrm{E}-6$ & $3.5 \mathrm{E}-6$ \\
\hline Turbine Building (F2) & $4.5 \mathrm{E}-7$ & $2.2 \mathrm{E}-8$ & $3.6 \mathrm{E}-7$ & $8.3 \mathrm{E}-7$ \\
\hline Auxiliary Building (F3) & $4.7 \mathrm{E}-8$ & $4.3 \mathrm{E}-8$ & $1.2 \mathrm{E}-8$ & $1.0 \mathrm{E}-7$ \\
\hline Auxiliary Building (F4) & $1.6 \mathrm{E}-7$ & $5.7 \mathrm{E}-8$ & $6.7 \mathrm{E}-8$ & $2.8 \mathrm{E}-7$ \\
\hline Safeguard Area (F5) & $2.0 \mathrm{E}-7$ & $8.9 \mathrm{E}-8$ & $9.4 \mathrm{E}-8$ & $3.8 \mathrm{E}-7$ \\
\hline Spray in Containment (F6) & - & - & - & - \\
\hline \hline Mechanical Equipment Room No. \#3 (F7) & $1.0 \mathrm{E}-8$ & $1.5 \mathrm{E}-8$ & $7.8 \mathrm{E}-9$ & $3.3 \mathrm{E}-8$ \\
\hline Total-Flood & $2.8 \mathrm{E}-6$ & $3.2 \mathrm{E}-7$ & $2.0 \mathrm{E}-6$ & $5.1 \mathrm{E}-6$ \\
\hline
\end{tabular}

ruptures upstream of the condenser water box and inlet valves. At Surry the circulating water system is gravity fed from a very large capacity intake canal and it may not be isolated quickly enough. This is in contrast to other common design arrangements in which dedicated pumps provide the required cooling water for the system. In these designs, stopping the pumps would effectively isolate the system, limiting potential water outflow.

The potential draining of the intake canal inventory in the turbine building is dominant because of a plant-specific spatial interdependence. For both units the ESGR are located in the service building on the same elevation as the turbine building basement. These areas are separated by a fire door with 2 -foot- high flood dikes in front of them. A large-scale flood could overflow the dikes and enter into the two-unit ESGR, leading to the potential loss of emergency power in both units, including the loss of residual heat removal (RHR) stub busses. The normal offsite power supply to the plant would not be affected since the normal switch gear room is located at a higher elevation in the service building.

Another important contributor to the internal flood $\mathrm{CDF}$ is flood events originating in or entering into the auxiliary building. These flood scenarios, mainly supply pipe ruptures from the RWST, result in the loss of all component cooling water (CCW) and consequently the RHR function at the plant. This, coupled with the unavailability of the RWST inventory to be injected into the reactor core, leads to core damage. Again, the plant-specific spatial arrangement of piping and equipment is the main reason for the development of the accident scenario and its risk significance.

\subsubsection{Results from Seismic Analysis}

Table 7 shows the base case results. The base case consists of the Surry plant (systems and fragilities) at the Surry site with Electric Power Research Institute (EPRI) ${ }^{[16]}$ and Lawrence Livermore National Laboratory (LLNL) ${ }^{[17]}$ seismic hazard curves. In this table, the mean, median, 5th percentile, and 95th percentile frequencies of the two plant operating states are shown. It is seen from the table that mean annual frequency of the two plant operating states is less than $10^{-6}$ per year using either the LLNL or the EPRI seismic hazard curves. Therefore, we conclude that the seismic contribution to mean annual core damage frequency during both POS 6 and POS 10 is very small at Surry Unit 1.

The comparison of CDF results is also shown in Table 7. From examining the table, several important observations emerge:

- During shutdown conditions, the total annual mean CDF arising from earthquakes is small compared with the CDF arising from internal initiators: a factor of about 15 smaller for the LLNL seismic hazard curves and a factor of about 60 smaller using the EPRI hazard curves.

- The seismic mean $\mathrm{CDF}$ during shutdown is small compared with the mean $\mathrm{CDF}$ at full power from seismic initiators from NUREG-1150: a factor of about 350 times smaller for the LLNL hazard curves and about 300 times smaller for the EPRI hazard curves. 
- The error factor $(E F)$ in this seismic study is significantly greater than the $E F$ in the CDF from internal initiators during shutdown This is primarily caused by the large uncertainty in the seismic hazard curves but another contribution arises from the uncertainty in the seismic fragilities.

A number of important insights emerge from this Surry analysis, including:

\section{Core-damage frequency}

The core damage frequency for earthquake-initiated accidents during refueling outages in POS 6 and POS 10 is found to be low in absolute terms, below 10-6/year. The reasons for this are (1) Surry's capacity to respond to earthquakes during shutdown is excellent, well above its design basis and similar to its ability to respond to earthquakes during full power conditions; (2) the Surry site is one of the least seismically active locations in the United States; (3) the Surry plant is only in POS 6 and POS 10 (combined) for an average (mean) of 6.6 percent of the time. The core damage frequencies are also low relative to the frequencies during POS 6 and POS 10 for internal initiators. This can be seen in Table 7 .

\section{The results are plant-specific}

We believe that the results for Surry are highly plant-specific, in the sense that the seismic capacities, the specific sequences that are found to be most important, and the seismicity of the site are all difficult to generalize to other reactors elsewhere.

\section{Shutdown seismic sequences are similar to full-power seismic sequences}

Nevertheless, it is important to observe that all of the sequence types, components, and human errors that emerge in the key sequences in this analysis are similar or identical to sequences, components, and human errors that appear in typical full-power seismic PRAs. That is, nothing that has arisen as important in this study appears to be unique to earthquakes occurring during shutdown conditions. Whether this observation can be generalized to other reactors at other sites is not known to us.

\section{Sensitivities}

Sensitivity studies reveal that if the Surry reactor were moved to the Zion site in Illinois (a typical Midwestern site) or the Pilgrim site in Massachusetts (one of the most seismically active sites among all of the reactor sites in the eastern United States), the mean annual CDF from this study would increase by factors of about 1.8 and 10, respectively.

\section{Uncertainties}

While there are significant uncertainties in the numerical values of core-damage frequencies found in this study (see Table 7), the above conclusions are relatively robust --- they do not depend on the detailed numerical values found.

\subsection{Level 2/3 Results}

Table 10 presents statistical measures of the distributions for seven consequence measures for accidents during midloop operation obtained from this study. Similar statistical measures for full power operation obtained from the NUREG1150 study of Surry are also included in the table. Table 10 indicates that the mean risk of offsite early health effects is more than on order of magnitude lower for accidents during midloop operation than for full power. This is due to the natural decay of the radionuclide inventory (because the accidents occur a long time after shutdown), particularly the short-lived isotopes of iodine and tellurium, which are primarily associated with early health effects. The distributions obtained for population dose ( 50 miles and 1000 miles) for midloop and full power operation are very similar. However, the distributions for latent cancer fatalities differ by a factor of about three. The midloop study used the latest version of the MACCS code, ${ }^{[18]}$ which incorporates the BEIR $V^{[19]}$ update to the latent cancer versus dose relationship, whereas NUREG-1150 used an older version of MACCS. The latest BEIR V update gives approximately a factor of three higher latent cancers for the same value of population dose.

The accident sequences in which operators did not achieve containment isolation were the largest contributors to the core damage frequency during midloop operation and even larger contributors to the offsite risk estimates. Therefore, during midloop operation the probability of loss of containment integrity conditional on core damage was assessed to be high. 
Comparison of Distributions of Risks for Midloop and Full Power Operation (All Values per Reactor Year; Population Doses in P-Sv per Year)

\begin{tabular}{|c|c|c|c|c|c|c|c|c|c|c|}
\hline & \multicolumn{2}{|c|}{ 5th Percentile } & \multicolumn{2}{|c|}{ Median } & \multicolumn{2}{|c|}{ Mean } & \multicolumn{2}{|c|}{ 95th Percentile } & \multicolumn{2}{|c|}{ Sigma } \\
\hline & $\begin{array}{l}\text { Mid- } \\
\text { Loop }\end{array}$ & $\begin{array}{l}\text { Full- } \\
\text { Power }\end{array}$ & $\begin{array}{l}\text { Mid- } \\
\text { Loop }\end{array}$ & $\begin{array}{l}\text { Full- } \\
\text { Power }\end{array}$ & $\begin{array}{l}\text { Mid- } \\
\text { Loop }\end{array}$ & $\begin{array}{c}\text { Full- } \\
\text { Power }\end{array}$ & $\begin{array}{l}\text { Mid- } \\
\text { Loop }\end{array}$ & $\begin{array}{c}\text { Full- } \\
\text { Power }\end{array}$ & $\begin{array}{l}\text { Mid- } \\
\text { Loop }\end{array}$ & $\begin{array}{c}\text { Full- } \\
\text { Power }\end{array}$ \\
\hline Early Fatalities & $1.26 \mathrm{E}-10$ & $7.60 \mathrm{E}-10$ & 3.57E-9 & $7.00 \mathrm{E}-8$ & $4.90 \mathrm{E}-8$ & $2.00 \mathrm{E}-6$ & $1.59 \mathrm{E}-7$ & $5.40 \mathrm{E}-6$ & $1.69 \mathrm{E}-7$ & N.A \\
\hline $\begin{array}{l}\text { Latent Fatalities } \\
\text { within } 50 \mathrm{mi}\end{array}$ & $1.55 \mathrm{E}-4$ & N.A. & $8.34 \mathrm{E}-4$ & N.A & $2.46 \mathrm{E}-3$ & N.A. & $8.78 \mathrm{E}-3$ & N.A. & $3.68 \mathrm{E}-3$ & N.A. \\
\hline $\begin{array}{l}\text { Latent Fatalities } \\
\text { within } 1000 \mathrm{mi}\end{array}$ & $7.97 \mathrm{E}-4$ & $3.10 \mathrm{E}-4$ & 5.35E-3 & $2.20 \mathrm{E}-3$ & $1.57 \mathrm{E}-2$ & $5.20 \mathrm{E}-3$ & $5.50 \mathrm{E}-2$ & $1.90 \mathrm{E}-2$ & $2.52 \mathrm{E}-2$ & N.A. \\
\hline $\begin{array}{l}\text { Population Dose } \\
\text { within } 50 \mathrm{mi}\end{array}$ & 3.77E-3 & $5.90 \mathrm{E}-3$ & $1.98 \mathrm{E}-2$ & $2.70 \mathrm{E}-2$ & S.79E-2 & $5.80 \mathrm{E}-2$ & $1.89 \mathrm{E}-1$ & $2.50 \mathrm{E}-1$ & 8.77E-2 & N.A \\
\hline $\begin{array}{l}\text { Population Dose } \\
\text { within } \\
1000 \mathrm{mi}\end{array}$ & $1.87 \mathrm{E}-2$ & $1.90 \mathrm{E}-2$ & $1.2 \mathrm{SE}-1$ & $1.30 \mathrm{E}-1$ & $3.66 \mathrm{E}_{-}-1$ & $3.10 \mathrm{E}-1$ & $1.29 \mathrm{E}+00$ & $1.20 \mathrm{E}+00$ & $5.90 \mathrm{E}-1$ & N.A \\
\hline $\begin{array}{l}\text { Individual Early } \\
\text { Fatalities Risk } \\
\text { within } 1 \mathrm{mi}^{\mathbf{2}}\end{array}$ & $6.00 \mathrm{E}-12$ & $1.40 \mathrm{E}-11$ & $1.27 \mathrm{E}-10$ & 8.70E-10 & $1.74 \mathrm{E}-9$ & $1.60 \mathrm{E}-8$ & $6.94 \mathrm{E}-9$ & $4.90 \mathrm{E}-8$ & 5.52E-9 & N.A. \\
\hline $\begin{array}{l}\text { Individual Latent } \\
\text { Fatalities Risk } \\
\text { within } 10 \mathrm{mi}^{\mathrm{a}}\end{array}$ & $1.20 \mathrm{E}-10$ & $1.60 \mathrm{E}-10$ & $7.48 \mathrm{E}-10$ & $4.90 \mathrm{E}-10$ & 2.09E-9 & $1.70 \mathrm{E}-9$ & 7.10E-9 & 8.10E-9 & $3.01 \mathrm{E}-9$ & N.A. \\
\hline
\end{tabular}

N.A - Not available

NRC quantitative health objectives:

- Individual early fatality risk within one mile to be less than $5 \times 10^{-7}$ per reactor year.

- Individual latent cancer fatality risk within 10 miles to be less than $2 \times 10^{6}$ per reactor year.

In comparison, in the full power study, accident sequences that lead to station blackout were the largest contributors to core damage frequency but not to the offsite risk estimates. This is because containment performance at Surry was found to be very good for this class of accidents, even if the molten core penetrates the lower head of the reactor vessel. Therefore accidents with lower frequencies but higher source terms which bypassed the containment, such as interfacing system loss-of-coolant accidents (ISLOCAs) and steam generator tube ruptures (SGTRs) were found to be the largest contributors to mean risk estimates in the full power study. Thus the loss of containment integrity conditional on core damage was determined to be small for severe accidents at full power. Therefore, although the core damage frequency distributions are an order of magnitude lower for midloop operation than for full-power operation, the frequencies of relatively large source terms are similar in both studies and hence the distributions for population dose are also similar.

The scoping estimates of onsite doses indicate that the parking lot dose rates for accidents involving unisolated containment were high. This would limit the ability to take corrective actions, which cannot be performed from the control room, for this class of accidents.

The results of this study are compared with the NRC safety goals only for the two quantitative health objectives identified in the NRC's policy statement of August 1986. These objectives deal with individual early fatality and latent cancer fatality risks within 1 mile and 10 miles of the site, respectively. The numerical values of these objectives are given in Table 10. The 95th percentile of the distribution for individual latent cancer fatality risk falls more than an order of magnitude below the objective. The 95th percentile of the distribution for individual early fatality risk falls over two orders of magnitude below the corresponding health objective.

The main finding of the study is that during midloop operation the risks of consequence measures related to long-term health effects -- latent cancer fatalities and population dose -- are high; they are comparable to those at full power, despite the much lower level of the decay heat and the radionuclide inventory. The reason for this is that containment is likely to be unisolated for a significant fraction of the accidents initiated during midloop operation so the releases to the environment are potentially large and the radionuclide species which mostly contribute to long-term health effects (such as cesium) have long half-lives. Accident sequences involving failure to correctly diagnose the situation or take proper actions are the largest contributors to the integrated risk. Another finding of the study is that the risk of early fatalities is low despite the unisolated containment owing to the decay of the short-lived radionuclide species such as iodine and 
tellurium, which contribute to early fatality risk. The integrated risk estimates have a range of uncertainty extending over approximately two orders of magnitude from the 5 th to the 95 th percentile of the distribution.

\section{Comparison with Full Power Study}

The mean core damage frequency for accidents during midloop operation is about an order of magnitude lower than the mean frequency of accidents caused by internal events at full power. However, the risk distributions obtained for comparable long-term health consequences are very similar in the two studies. What this finding implies is that the lower decay heat and lower radionuclide inventory of the midloop operating state, compared with full power, is offset by the likelihood of containment being unisolated. Finally, the mean risk of early health effects is more than an order of magnitude lower for accidents during midloop operation than during full power operation. This is due to the natural decay of those radionuclide species which have the greatest impact on early fatality risk because accidents during midloop operation occur a long time after shutdown.

\subsection{CONCLUSIONS}

This study was successful in developing a methodology to estimate the risk associated with the operation of a PWR during midloop operation. The methodology developed and the lessons learned from its application provide the NRC with new tools that could be used in subsequent analyses. The study concentrated the effort on midloop operation only. The core damage frequency contributions of other low-power and shutdown POSs were analyzed only in the coarse screening analysis of the Phase 1 study, and remain to be analyzed in the future.

The following sections summarize the conclusions of the study.

\subsubsection{Level 1 Conclusions}

\section{Internal Events}

This study shows that the core damage frequency resulting from internal events during midloop operation at the Surry plant is lower than that of power operation. This is mainly due to the much smaller fraction of time that the plant is at midloop. The conditional core damage frequency, which provides a measure of the vulnerability of the plant configuration with respect to core damage, is actually higher than that of power operation.

The time window approach developed in this study provides a more realistic approach to accounting for the changing decay heat during shutdown. Without it, the core damage frequency estimates could be an order of magnitude higher.

This study discovered that only a few procedures are available for mitigating accidents that may occur during shutdown. Procedures written specifically for shutdown accidents would be useful and should be based on realistic thermal hydraulic analyses.

We assumed that a reduced-inventory checklist was followed, and found that for equipment not on the checklist, maintenance unavailability was a dominant contributor to system unavailability. However, the checklist is believed to be sufficient for ensuring the availability of essential equipment. The dominant cause of damage is operator errors. We recognize that there is very large uncertainty in the human error probabilities used in this study.

\section{Internal Fires}

A comparison of the fire-induced core damage frequency during midloop operation with that of power operation shows that, although the plant spends much less time in midloop, the core damage frequencies are comparable. The main reason is that the routing of the cables of the equipment needed to support RHR operation or mitigate an accident during midloop operation is such that a single fire at a few critical locations can damage almost all the equipment needed, while during power operation there are fewer critical locations.

Risk-significant scenarios are found mainly in the ESGR and the cable vault and tunnel (CVT). In the ESGR, several important scenarios (which are also the most risk-significant ESGR scenarios) occur in locations where many cables for the $\mathrm{H}$ and the $\mathrm{J}$ emergency divisions come together in a close proximity. In the CVT, the tunnel part is a constrained space, where damage would quickly propagate to both divisions (serving many different peices of emergency equipment). In the containment, the risk significance stems from the relatively high fire frequency and nonseparation of the two RHR divisions. POSs D6 and R6 are much more risk significant than R10, with POS D6 more significant than R6. 
Windows 1,2 , and 3 are much more important than window 4 , and windows 1 and 2 are more important than window 3 . Window 2 is the most risk-significant window.

\section{Internal Floods}

The internal flood CDF is dominated by turbine building flood events. These events are primarily initiated by either valve or expansion joint failures in the main inlet lines of the circulating water system. These failures may lead to pipe ruptures upstream of the condenser water box and inlet valves. At Surry the circulating water system is gravity fed from a very large capacity intake canal and it may not be isolated quickly enough. This is in contrast to other common design arrangements where dedicated pumps move the required cooling water through the system.

The potential draining of the intake canal inventory in the turbine building is dominant because of a plant-specific spatial interdependence. For both units the ESGR are located in the service building on the same elevation as the turbine building basement. These areas are separated by a fire door with 2-foot-high flood dikes in front of them. A large-scale flood could overflow the dikes and enter into the two-unit ESGR, leading to the potential loss of emergency power in both units, including the loss of stub busses that support the RHR pumps. The normal offsite power supply to the plant would not be affected since the normal SGR is located at a higher elevation in the service building.

The flood-initiating event analysis indicated that the shutdown, and specifically the midloop operational period, does not pose a unique flood risk with the exception of flood events coupled with loop isolation in time windows 2,3 , and 4 . In general, the risk from flood events is relatively significant and is dominated by potential flood events into the ESGR coupled with loop isolation.

\section{Seismic Events}

The core damage frequency for earthquake-initiated accidents during refueling outages in POS 6 and POS 10 is found to be low in absolute terms, below 10-6/year. The reasons for this are (1) Surry's capacity to respond to earthquakes during shutdown is excellent, well above its design basis and similar to its ability to respond to earthquakes during full-power conditions; (2) the Surry site is one of the least seismically active locations in the United States; (3) the Surry plant is only in POS 6 and POS 10 (combined) for an average (mean) of 6.6 percent of the time.

The seismic mean CDF during shutdown is small compared with the mean $C D F$ at full power from seismic initiators from NUREG-1150: a factor of about 350 times smaller for the LLNL hazard curves and about 300 times smaller for the EPRI hazard curves.

\subsubsection{Level 2/3 Conclusions}

\section{Comparison with Full Power Study}

The mean core damage frequency for accidents during midloop operation is about an order of magnitude lower than the mean frequency of accidents caused by internal events at full power. However, the risk distributions obtained for comparable long-term health consequences are very similar in the two studies. What this finding implies is that the lower decay heat and lower radionuclide inventory of the midloop operating state, compared with full power, are offset by the likelihood of the containment being unisolated. Finally, the mean risk of early health effects is more than an order of magnitude lower for accidents during midloop operation than during full power operation. This is due to the natural decay of those radionuclide species which have the greatest impact on early fatality risk because accidents during midloop operation occur a long time after shutdown.

\section{Comparison With the Safety Goals}

The results of this study are compared against the NRC safety goals only for the two quantitative health objectives identified in the NRC's policy statement of August 1986. These objectives deal with individual early fatality and latent cancer fatality risks within 1 mile and 10 miles of the site, respectively. The numerical values of these objectives are given in Table 10. The 95th percentile of the distribution for individual latent cancer fatality risk falls more than an order of magnitude below the objective. The 95th percentile of the distribution for individual early fatality risk falls over two orders of magnitude below the corresponding health objective. 


\section{References}

[1] D. W. Whitehead et al., "Evaluation of Potential Severe Accidents During Low Power and Shutdown Operations at Grand Gulf, Unit 1 Main Report (Sections 1-9)," NUREG/CR-6143, SAND93-2440, Vol. 2, Part 1A, Sandia National Laboratories, June 1994.

[2] D. W. Whitehead et al., "Evaluation of Potential Severe Accidents During Low Power and Shutdown Operations at Grand Gulf, Unit 1 Main Report (Sections 11-14)," NUREG/CR-6143, SAND93-2440, Vol. 2, Part 1C, Sandia National Laboratories, June 1994.

[3] J. Lambright et al., "Evaluation of Potential Severe Accidents During Low Power and Shutdown Operations at Grand Gulf, Unit 1 Analysis of Core Damage Frequency from Internal Fire Events for Plant Operational State 5 During an Refueling Outage, "NUREG/CR-6143, SAND93-2440, Vol. 3, Sandia National Laboratories, July 1994.

[4] V. Dandini et al., "Evaluation of Potential Severe Accidents During Low Power and Shutdown Operations at Grand Gulf, Unit 1 Analysis of Core Damage Frequency from Internally Induced Flooding Events for Plant Operational State 5 During an Refueling Outage, "NUREG/CR-6143, SAND93-2440, Vol. 4, Sandia National Laboratories, July 1994.

[5] R. J. Budnitz et al., "Evaluation of Potential Severe Accidents During Low Power and Shutdown Operations at Grand Gulf, Unit 1 Analysis of Core Damage Frequency from Seismic Events for Plant Operational State 5 During an Refueling Outage," NUREG/CR-6143, Vol. 5, Future Resources Associates, Inc., Berkeley, CA, August 1994.

[6] T. D. Brown et al., "Evaluation of Potential Severe Accidents During Low Power and Shutdown Operations at Grand Gulf, Unit 1 Evaluation of Severe Accident Risk for Plant Operational State 5 During an Refueling Outage Main Report," NUREG/CR-6143, SAND93-2440, Vol. 6, Part 1, Sandia National Laboratories, to be published.

[7] T. D. Brown et al., "Evaluation of Severe Accident Risks: Grand Gulf Unit 1," NUREG/CR-4551, SAND861309, Vol. 6, Rev. 1, Sandia National Laboratories, December 1990.

[8] T.L Chu et al., "Evaluation of Potential Severe Accidents during Low Power and Shutdown Operations at Surry Unit-1, Analysis of Core Damage Frequency from Internal Events During Mid-Loop operations, Main Report (Chapter 1-6)," NUREG/CR-6144, BNL-NUREG-52399, Vol. 2, Part 1A, Brookhave National Laboratory, June, 1994.

[9] T.L Chu et al., "Evaluation of Potential Severe Accidents during Low Power and Shutdown Operations at Surry Unit-1, Analysis of Core Damage Frequency from Internal Events During Mid-Loop operations, Main Report (Chapter 7-12)," NUREG/CR-6144, BNL-NUREG-52399, Vol. 2, Part 1B, Brookhave National Laboratory, June, 1994.

[10] Z. Musicki et al., "Evaluation of Potential Severe Accidents during Low Power and Shutdown Operations at Surry Unit-1, Analysis of Core Damage Frequency from Internal Fires During Mid-Loop operations, Main Report," NUREG/CR-6144, BNL-NUREG-52399, Vol. 3, Part 1, Brookhave National Laboratory, July, 1994.

[11] P. Kohut, "Evaluation of Potential Severe Accidents during Low Power and Shutdown Operations at Surry Unit-1, Analysis of Core Damage Frequency from Internal Floods During Mid-Loop operations, " NUREG/CR-6144, BNL-NUREG-52399, Vol. 4, Brookhave National Laboratory, July, 1994.

[12] R. J. Budnitz et.al., "Evaluation of Potential Severe Accidents during Low Power and Shutdown Operations at Surry Unit-1, Analysis of Core Damage Frequency from Seismic Events During Mid-Loop operations," NUREG/CR-6144, Vol. 5, Future Resources Associates Inc., August, 1994.

[13] J. Jo et.al., "Evaluation of Potential Severe Accidents during Low Power and Shutdown Operations at Surry Unit1, Evaluation of Severe Accident Risks During Mid-loop Operations," NUREG/CR-6144, BNL-NUREG-52399, Vol. 6, Brookhave National Laboratory, to be published.

[14] U. S. Nuclear Regulatory Commission, "Severe Accident Risks: An Assessment for Five U. S. Nuclear Power Plants," NUREG-1150, Vols. 1-3, December 1990-January 1991. 
[15] Virginia Power, Surry Nuclear Power Plant, Individual Plant Examination Program, August 1991.

[16] Electric Power Research Institute, "Probabilistic Seismic Hazard Evaluations at Nuclear Power Plant Sites in the Central and Eastern United States: Resolution of the Charleston Earthquake Issue," Prepared by Risk Engineering, Inc., Yankee Atomic Power Company and Woodward Clyde Consultants, EPRI Report NP-6395-D, April 1989.

[17] D.L. Bernreutr, J.B. Savy, R.W. Mensing and J.C. Chen, "Seismic Hazard Characterization of 69 Nuclear Plant Sites East of the Rocky Mountains," NUREG/C-5250, Lawrence Livermore National Laboratory, January 1989.

[18] Chanin, D., J. Rollstin, J. Foster, and L. Miller, "MACCS Version 1.5.11.1: A Maintenance Release of the Code," NUREG/CR-6059, October 1993.

[19] National Research Council Committee on Biological Effects of Ionizing Radiation (BEIR V), "Health Effects of Exposure to Low Levels of Ionizing Radiation," National Academy of Sciences, Washington, DC, 1990.

\section{DISCLAIMER}

This report was prepared as an account of work sponsored by an agency of the United States Government. Neither the United States Government nor any agency thereof, nor any of their employees, makes any warranty, express or implied, or assumes any legal liability or responsibility for the accuracy, completeness, or usefulness of any information, apparatus, product, or process disclosed, or represents that its use would not infringe privately owned rights. Reference herein to any specific commercial product, process, or service by trade name, trademark, manufacturer, or otherwise does not necessarily constitute or imply its endorsement, recommendation, or favoring by the United States Government or any agency thereof. The views and opinions of authors expressed herein do not necessarily state or reflect those of the United States Government or any agency thereof. 